\title{
PROBIOTIC-YEAST IMPROVES PERFORMANCE INDICATORS IN BROILER CHICKENS: EVIDENCE FROM META-ANALYSIS
}

\author{
OgBuewu, I. P. ${ }^{*}-$ OKORO, V. M. ${ }^{2}-$ MbAJIORGU, C. A. ${ }^{1}$ \\ ${ }^{I}$ Department of Animal Agriculture and Animal Health, University of South Africa, Florida \\ 1710, South Africa \\ ${ }^{2}$ Department of Animal Science and Technology, Federal University of Technology, PMB 1526 \\ Owerri, Nigeria \\ *Corresponding author \\ e-mail: ogbueip@unisa.ac.za,dr.ogbuewu@gmail.com \\ (Received $15^{\text {th }}$ Oct 2019; accepted $8^{\text {th }}$ Jan 2020)
}

\begin{abstract}
Antibiotics modulate gut microbiomes and enhance broiler chicken productivity. Nevertheless, their use in chicken nutrition has been linked to the spread of resistant strains of bacteria. Studies have shown that probiotic-yeast improves the productivity of broiler chickens. However, agreement has not been reached among investigators as to whether yeast improves the production indices of broiler chickens. The objective of this meta-analysis therefore was to determine the effect of yeast supplementation on feed consumption (FC), feed conversion ratio (FCR) and body weight gain (BWG) in broiler chicken using meta-analysis. The study focused on published primary studies comparing broiler chickens fed diet supplemented with yeast versus without yeast. Sixteen published primary studies were included in the meta-analysis. Results of pooled effects estimate revealed that yeast supplementation improved FCR $(p<0.001)$, BWG $(p<0.001)$ and reduced FC $(p<0.001)$ in broiler chickens. The results of sub-analysis indicated that broiler chickens that received yeast at $<10 \mathrm{~g} / \mathrm{kg}$ diet had better performance than those that received yeast at $10 \mathrm{~g} / \mathrm{kg}$ feed and $>10 \mathrm{~g} / \mathrm{kg}$ feed. The chosen moderators were predictors of study effect observed in the meta-analysis. It is concluded that yeast can be used as a performance enhancer in broiler chickens instead of antibiotics.
\end{abstract}

Keyword: beneficial microbes, meat-typed chickens, productivity, meta-analysis, meta-regression

\section{Introduction}

Broiler chicken farming plays a vital part in supporting the livelihoods of most households in many parts of the world, because of its role as a source of animal protein. Incidentally, several households in developing nations, still regard poultry products as luxury (Adene and Oguntade, 2006). This has been attributed to the high cost of poultry products driven mainly by the elevated feed price, which led poultry nutritionist to search for feed additives with the potential to increase feed digestion and nutrient uptakes (Gadde et al., 2017). Antibiotics, one of such feed additives has been reported to modulate gut microbiomes, enhance feed efficiency, boost growth rate as well as deter the emergence of diseases in chickens (Costa et al., 2017). Regardless of the established positive actions of in feed antibiotics in boosting growth performance in chickens, their use has been tied to the proliferation of resilient strains of bacteria and meat with remnants of antibiotics (Kabir et al., 2004; Chen et al., 2017; Gadde et al., 2017) which is a threat to public health (Kabir et al., 2004; Piątkowska et al., 2012). Although, views are mixed on whether the use of antibiotics in poultry feed can transfer resistance genes from animals to humans (Gadde et al., 2017), consumers of poultry meat were increasingly concerned about the risk of continued use of antibiotics in animal feeds (Kabir et al., 2004; Piątkowska et al., 
2012). This ugly development called for an investigation into the use of probiotics as an alternative to antibiotics in broiler nutrition (Ahmed et al., 2015; Gao et al., 2017; Ogbuewu et al., 2019).

Probiotics are living organisms that elicit positive health effects in animal and humans when included in the diet at the right proportions (FAO, 2016). The beneficial health property of probiotics can be ascribed to either its ability to modulate gut microbiomes or their direct nutritional effect (Saulnier, 2007; Shareef and Al-Dabbagh, 2009). Yeast (Saccharomyces cerevisiae), one of the commonly used probiotics in both human and animal food is a single-celled organism that measures about 3 to 4 microns in size. Yeast is rich in protein and amino acids (Gomes et al., 2014; Ogbuewu et al., 2019) as well as vitamin B complex and minerals (USDA, 2018). Chand et al. (2014) reported that yeast contains $93.00 \%$ dry matter, $1.00 \%$ ether extract, $44.40 \%$ crude protein, $2.70 \%$ crude fibre, $0.12 \%$ calcium and $1.40 \%$ phosphorus. Indisputably, the results of the production parameters of broiler chickens fed yeast supplemented diets in literature as reported by several authors were disaggregated and conflicting, hence calling for evidence synthesis. Evidently, there are several studies on the actions of yeast on broiler performance (Paryard and Mahmoudi, 2008; Ezema, 2013; Ahmed et al., 2015; Chen et al., 2017), and many have undoubtably shown that yeast enhance broiler chicken productivity (Ezema and Ugwu, 2014; Ogbuewu et al., 2019). Earlier reviews conducted to ascertain the beneficial effect of yeast on broiler chicken performance, however, were narrative, which is bias-friendly due to non-repeatability of the results and lacked the ability to manage large datasets. For example, Ezema and Ugwu (2014) did a narrative review of published studies of the effect of probiotic-yeast on broiler productivity and discovered that yeast improve growth rate and nutrient digestibility in chickens. Incongruity, a recent narrative review by Ogbuewu et al. (2019) found disparity on production data of broiler chickens fed yeast supplemented diets. The current study aims to use meta-analytical technique to identify and quantify several variables that affect the outcomes of the effect of probiotic yeast on the growth performance indices of broiler chickens.

\section{Materials and methods}

\section{Selection guidelines and ethical approval}

The main criteria for selecting the primary studies included in this meta-analysis were: randomized and controlled tests (RCTs) in diseased-free broiler chickens fed yeast supplemented diets. Studies were included if peer-reviewed and published in English. Study reported at least one of these growth performance indices (FC, FCR and BWG) and a dispersion metric such standard error (SE), standard deviation (SD) or 95\% confidence interval (CI) for each effect size. This study was conducted at the University of South Africa during the months of June to September 2019. Literature search and data analysis were conducted in line with the guidelines of the University of South Africa Ethics Committee.

\section{Data sources, extraction and data integrity}

The investigators independently searched for articles in PubMed, Scopus and Google scholar databases from 1999 to 2017. Studies were panel-selected to guarantee the reliability of outcome of the meta-analysis, which relies on the validity of papers that 
make up the database. Yeast* and broiler chickens* were included in the search conditions. Articles were evaluated, and those that met the selection guidelines were selected. Information on the surname of the first author, the year the study was published, broiler breed, yeast supplementation level, duration of yeast supplementation, outcomes of interest (FC, FCR, BWG) and measures of variance (SE, $\mathrm{SD}$ or $\mathrm{p}$-value) from the papers included in the meta-analysis are presented in the supplementary file. Most of the articles assessed did not report the yeast type used and the failure of the authors to obtain extra information from the corresponding author led to the removal of yeast type from the a priori selection criteria that an article must meet in order to be included in the meta-analysis. Furthermore, where the SD was not supplied, but can be estimated from SE, where it is reported using the method (Higgins and Deeks (2011).

\section{Statistical analysis}

Data analysis was performed in Open Meta-analyst for Ecology and Evolution (OpenMEE) software and forest plots were produced (Wallace et al., 2016). Continuous variable results (FC, BWG and FCR) were evaluated as the difference between the groups in yeast treatment and control with 95\% CI. Q-statistic (DerSimonian and Laird, 1986) and $I^{2}$ - statistic; (Higgins et al., 2003) were used to calculate heterogeneity. Pooled effects estimate of the responses of broiler chickens to yeast supplementation were calculated using the DerSimonian and Laird (1986) random-effects model (REM). The REM selection is based on the premise that information used in the current study were not the same, therefore, the variance must be split into variance within and variance between studies plus sampling error (Borenstein et al., 2009).

For robustness of our results, we used sensitivity analysis which according to Lean et al. (2009) is used to assess the impacts of studies judged to be deviant or to have an undue influence on the analysis. This was accomplished by leaving one study each time the analysis was conducted. The influence graph shows the global impact without each study. The magnitude of the effect of yeast supplementation on broiler chicken productivity may be affected by several explanatory variables (moderators). The moderators considered in this study matched the factors we assumed to predict the association between yeast supplementation and broiler performance. In the subgroup analysis, the data were stratified using the following modifiers (study continent, study country, supplementation level, duration of supplementation and broiler breed used) thought to influence the physiological traits of broiler chickens fed probiotic yeast. Subgroup analysis was not performed when there are comparatively few studies $(<3$ comparisons) in an individual stratum. The same variables used in the subgroup analysis were included as the modifier variables in the meta-regression (Dohoo et al., 2003). Meta-regression was used to examine whether the selected predictors (study continent, study country, yeast supplementation level, duration of yeast supplementation and breed of broiler used) explained any of the sources of heterogeneity.

Rosenberg's fail-safe number (Nfs) and funnel plots were used in this study to assess the existence of publication bias. Studies are said to have no publication bias when the funnel is inverted and symmetrical. Evidently, Jennions et al. (2013) have shown the robustness of meta-analysis results in the presence of publication bias regarded $\mathrm{Nfs}$ is greater than " $5(\mathrm{n}=$ number of effect sizes $)+10$ ". Forest plots (DerSimonian and Laird, 1986; IntHout et al., 2014) displayed the outcome of yeast intervention on broiler chicken productivity. Points to the left of the no effect line show a decline in the results 
of our parameters of interest, and the opposite demonstrates the reverse. The effect size is represented by individual square in the forest plot, while the upper and lower $95 \% \mathrm{CI}$ for the effect size are the line that joined the square. According to Leah et al. (2009), the inverse of the effect size variance is shown by the weight of each study, whereas the square box size is equivalent to the inverse variance of the estimates with larger square boxes suggesting greater weight. The pooled effects estimate depicts the dotted line with the diamond at the bottom making up 95\% CI. The pooled estimate was not significant when the diamond at the bottom is in contact with the no effect line (Koricheva et al., 2013). Effect sizes of approximately 0.2 and 0.5 are designated low and medium respectively, and large when they are more than 0.8 .

\section{Results}

\section{Overview of the articles included in the meta-analysis}

The literature search in PubMed, Scopus and Google scholar produced 64 articles evaluating the productive indices of broiler chickens fed yeast supplemented diets (Fig. 1). A total of 25 articles were excluded from the analysis because they were reported in animal species other than broiler chickens. Six papers were removed from the study because they were narrative reviews, while five papers were excluded because they reported only the abstract. Five articles were excluded from the meta-analysis because of they were not randomized, and the control group was missing. Seven articles were not considered suitable for the analysis because they did not report any of the outcomes of interest. For the analysis of FC, 16 studies (with 4874 birds and 62 comparisons) representing 10 study countries drawn from three study continents met the eligibility criteria (Table 1). The publications used in the meta-analysis to assess the effect of yeast supplementation on FC in broiler chickens span 18 years with first study published in 1999 and the most current published in 2017 (Table 1). The FCR analysis included 15 studies containing 59 comparisons and 4874 birds conducted in 10 study countries drawn from 3 study continents (Table 1), while 13 studies comprising 49 comparisons and 3930 birds were included for the assessment of the effect of yeast on BWG in broiler chickens (Table 1). Of the all articles used in the meta-analysis to evaluate the effect of yeast on production indices of broiler chickens, the oldest study was published in 1999 and the most recent published in 2017. Most of the studies used Ross followed with Arbor acres. Yeast was added via the feed in the present metaanalysis.

Table 1. Studies used to evaluate the effect of yeast-based diets on FC (g/bird), FCR and $B W G(\mathrm{~g} /$ bird $)$ of broiler chickens

\begin{tabular}{c|c|c|c|c|c|c|c|c}
\hline \multirow{2}{*}{ Study } & \multirow{2}{*}{ Year } & \multicolumn{5}{|c|}{ Sources of variation } & \multirow{2}{*}{ NOB } & \multirow{2}{*}{ Outcomes } \\
\cline { 3 - 8 } & & Study country & Study continent & SL $(\mathbf{g} / \mathbf{k g})$ & Broiler breeds & DS (d) & & \\
\hline Oyedeji et al. & 2008 & Nigeria & Africa & $0,0.2$ & Ross & 28 & 80 & FC, FCR, BWG \\
Al Mansour et al. & 2011 & Saudi Arabia & Asia & 0,1 & Ross & 21 & 120 & FC, FCR \\
Al Mansour et al. & 2011 & Saudi Arabia & Asia & $0,1.25$ & Ross & 21 & 120 & FC, FCR \\
Al Mansour et al. & 2011 & Saudi Arabia & Asia & $0,1.5$ & Ross & 21 & 120 & FC, FCR, BWG \\
Al Mansour et al. & 2011 & Saudi Arabia & Asia & 0,1 & Ross & 42 & 120 & FC, FCR \\
Al Mansour et al. & 2011 & Saudi Arabia & Asia & $0,1.25$ & Ross & 42 & 120 & FC, FCR \\
Al Mansour et al. & 2011 & Saudi Arabia & Asia & $0,1.5$ & Ross & 42 & 120 & FC, FCR \\
Njeru & 2013 & Kenya & Africa & $0,1.25$ & Arbor Acres & 21 & 80 & FC, FCR, BWG \\
Njeru & 2013 & Kenya & Africa & $0,0.63$ & Arbor Acres & 42 & 80 & FC, FCR, BWG
\end{tabular}




\begin{tabular}{|c|c|c|c|c|c|c|c|c|}
\hline El Fatah & $\mid 1999$ & Sudan & Africa & 0,25 & Ross & 42 & 60 & FC, FCR, BWG \\
\hline El Fatah & 1999 & Sudan & Africa & 0,50 & Ross & 42 & 60 & FC, FCR, BWG \\
\hline El Fatah & 1999 & Sudan & Africa & 0,75 & Ross & 42 & 60 & BWG \\
\hline El Fatah & 1999 & Sudan & Africa & 0,100 & Ross & 42 & 60 & FC, FCR, BWG \\
\hline Mohamed et al. & 2015 & Sudan & Africa & 0,10 & Hubbard & 21 & 80 & FC, FCR, BWG \\
\hline Mohamed et al. & 2015 & Sudan & Africa & 0,20 & Hubbard & 21 & 80 & FC, FCR, BWG \\
\hline Mohamed et al. & 2015 & Sudan & Africa & 0,30 & Hubbard & 21 & 80 & FC, FCR, BWG \\
\hline Mohamed et al. & 2015 & Sudan & Africa & 0,10 & Hubbard & 42 & 80 & FC, FCR, BWG \\
\hline Mohamed et al. & 2015 & Sudan & Africa & 0,20 & Hubbard & 42 & 80 & FC, FCR, BWG \\
\hline Mohamed et al. & 2015 & Sudan & Africa & 0,30 & Hubbard & 42 & 80 & FC, FCR, BWG \\
\hline Chen et al. & 2017 & Taiwan & Asia & $0,2.5$ & Arbor Acres & 21 & 120 & $\mathrm{FC}, \mathrm{BWG}$ \\
\hline Chen et al. & 2017 & Taiwan & Asia & $0,2.5$ & Arbor Acres & 35 & 120 & FC, FCR, BWG \\
\hline Aluwong et al. & 2012 & Nigeria & Africa & 0,15 & Marshall & 42 & 100 & FC, FCR \\
\hline Aluwong et al. & 2012 & Nigeria & Africa & 0,20 & Marshall & 42 & 100 & FC, FCR \\
\hline Osman & 2006 & Sudan & Africa & $0,0.2$ & Lohman & 28 & 100 & FC, FCR, BWG \\
\hline Osman & 2006 & Sudan & Africa & $0,0.4$ & Lohman & 28 & 100 & FC, FCR, BWG \\
\hline Osman & 2006 & Sudan & Africa & $0,0.6$ & Lohman & 28 & 100 & FC, FCR, BWG \\
\hline Shareef and Al-Dabbagh & 2009 & Iraq & Asia & 0,5 & Faobrow CD & 21 & 40 & FC, FCR, BWG \\
\hline Shareef and Al-Dabbagh & 2009 & Iraq & Asia & 0,10 & Faobrow CD & 21 & 40 & FC, FCR, BWG \\
\hline Shareef and Al-Dabbagh & 2009 & Iraq & Asia & 0,15 & Faobrow CD & 21 & 40 & FC, FCR, BWG \\
\hline Shareef and Al-Dabbagh & 2009 & Iraq & Asia & 0,20 & Faobrow CD & 21 & 40 & FC, FCR, BWG \\
\hline Chand et al. & 2014 & Pakistan & Asia & $0,3.5$ & Hubbard & 35 & 60 & FC, FCR \\
\hline Chand et al. & 2014 & Pakistan & Asia & 0,7 & Hubbard & 35 & 60 & FC, FCR \\
\hline Chand et al. & 2014 & Pakistan & Asia & $0,10.5$ & Hubbard & 35 & 60 & FC, FCR \\
\hline Manal & 2012 & Egypt & Africa & 0,3 & Arbor Acres & 21 & 60 & FC, FCR, BWG \\
\hline Manal & 2012 & Egypt & Africa & 0,5 & Arbor Acres & 21 & 60 & FC, FCR, BWG \\
\hline Manal & 2012 & Egypt & Africa & 0,7 & Arbor Acres & 21 & 60 & FC, FCR, BWG \\
\hline Manal & 2012 & Egypt & Africa & 0,3 & Arbor Acres & 42 & 60 & FC, FCR, BWG \\
\hline Manal & 2012 & Egypt & Africa & 0,5 & Arbor Acres & 42 & 60 & FC, FCR, BWG \\
\hline Manal & 2012 & Egypt & Africa & 0,7 & Arbor Acres & 42 & 60 & FC, FCR, BWG \\
\hline Buba et al. & 2016 & Nigeria & Africa & 0,5 & White Rose & 28 & 102 & FC, FCR, BWG \\
\hline Buba et al. & 2016 & Nigeria & Africa & 0,10 & White Rose & 28 & 102 & FC, FCR, BWG \\
\hline Buba et al. & 2016 & Nigeria & Africa & 0,15 & White Rose & 28 & 102 & FC, FCR, BWG \\
\hline Buba et al. & 2016 & Nigeria & Africa & 0,20 & White Rose & 28 & 102 & FC, FCR, BWG \\
\hline Buba et al. & 2016 & Nigeria & Africa & 0,5 & White Rose & 56 & 102 & FC, FCR, BWG \\
\hline Buba et al. & 2016 & Nigeria & Africa & 0,10 & White Rose & 56 & 102 & FC, FCR \\
\hline Buba et al. & 2016 & Nigeria & Africa & 0,15 & White Rose & 56 & 102 & FC, FCR, BWG \\
\hline Buba et al. & 2016 & Nigeria & Africa & 0,20 & White Rose & 56 & 102 & FC, FCR, BWG \\
\hline Atul Shankar et al. & 2017 & India & Asia & 0,1 & Cobb & 42 & 144 & FC, FCR, BWG \\
\hline Atul Shankar et al. & 2017 & India & Asia & $0,1.5$ & Cobb & 42 & 144 & FC, FCR, BWG \\
\hline Atul Shankar et al. & 2017 & India & Asia & 0,2 & Cobb & 42 & 144 & FC, FCR, BWG \\
\hline Yalçin et al. & 2013 & Turkey & Europe & 0,1 & Ross & 21 & 70 & FC, FCR, BWG \\
\hline Yalçin et al. & 2013 & Turkey & Europe & 0,2 & Ross & 21 & 70 & FC, FCR, BWG \\
\hline Yalçin et al. & 2013 & Turkey & Europe & 0,3 & Ross & 21 & 70 & FC, FCR, BWG \\
\hline Yalçin et al. & 2013 & Turkey & Europe & 0,4 & Ross & 21 & 70 & FC, FCR, BWG \\
\hline Yalçin et al. & 2013 & Turkey & Europe & 0,1 & Ross & 42 & 70 & FC, FCR, BWG \\
\hline Yalçin et al. & 2013 & Turkey & Europe & 0,2 & Ross & 42 & 70 & FC, FCR, BWG \\
\hline Yalçin et al. & 2013 & Turkey & Europe & 0,3 & Ross & 42 & 70 & FC, FCR, BWG \\
\hline Yalçin et al. & 2013 & Turkey & Europe & 0,4 & Ross & 42 & 70 & FC, FCR, BWG \\
\hline Mohamed et al. & 2016 & Sudan & Africa & $0,2.5$ & Ross & 42 & 42 & FC, FCR, BWG \\
\hline Mohamed et al. & 2016 & Sudan & Africa & 0,5 & Ross & 42 & 42 & FC, FCR, BWG \\
\hline Mohamed et al. & 2016 & Sudan & Africa & 0,10 & Ross & 42 & 42 & FC, FCR \\
\hline Priya and Buba & 2013 & India & Asia & 0,5 & Ross & 36 & 100 & $\mathrm{FC}$ \\
\hline Priya and Buba & 2013 & India & Asia & 0,10 & Ross & 36 & 100 & $\mathrm{FC}$ \\
\hline
\end{tabular}

DS - duration of supplementation; SL - supplementation level; NOB - number of birds 


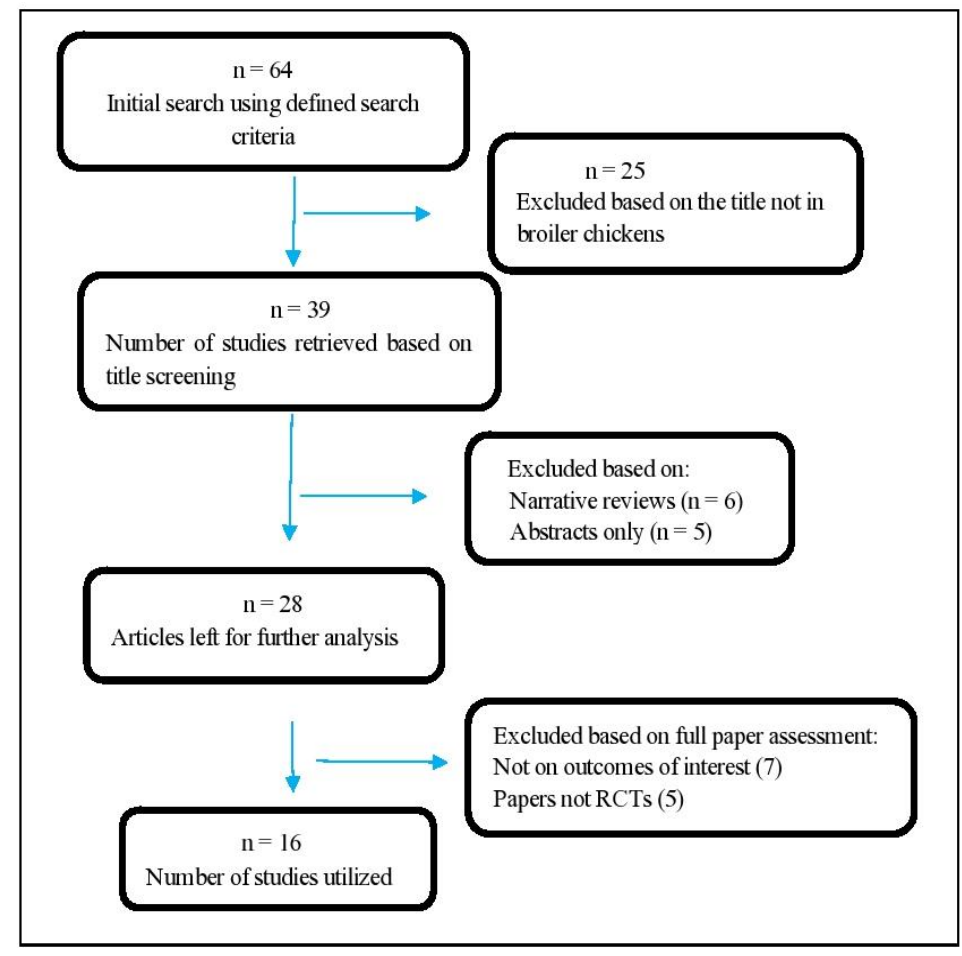

Figure 1. Flow chart of articles used for the meta-analysis

\section{Feed consumption (FC)}

The results of the overall effects estimate of yeast supplementation revealed that the incorporation of yeast in broiler diets reduced FC relative to broilers on control diet $\left(d=-0.429,95 \%\right.$ CI: -0.606 to $-0.253, I^{2}=89.59 \%, \mathrm{p}<0.001 ;$ Fig. 2$)$. The temporal trends of the outcome of yeast supplementation on FC of broiler chickens are presented in Figure 3. The results of stratified subgroup analysis of the relationship between modifier variables and FC in broiler chickens are presented in Table 2. When the analysis was disaggregated, the results of the grand mean indicated that FC was significantly influenced by the explanatory variables (study continent, study country, duration of supplementation, supplementation level, broiler breed used; $p<0.001$ ) following the removal of subgroup with one or two effect sizes. Disaggregation based on study continent, revealed that FC was not significantly reduced for studies performed in Africa, whereas studies conducted in Asia $(p<0.001)$ and Europe $(p<0.001)$ had significantly reduced FC. Results of the disaggregated studies of the effect of yeast on FC in broiler chickens based on study country showed that studies conducted in Pakistan, Egypt, India and Turkey were significantly different from zero ( $p<0.001)$. Broiler chickens fed diet supplemented with yeast at $<10 \mathrm{~g} / \mathrm{kg}$ feed had significantly reduced FC $(\mathrm{p}<0.001)$. However, there was no association between FC and supplementation level ( $>10 \mathrm{~g} / \mathrm{kg}$ feed, $\mathrm{p}=0.054 ; 10 \mathrm{~g} / \mathrm{kg}$ feed, $p=0.113$, respectively). Stratified subgroup analysis results showed that FC was significantly reduced in broiler chickens fed yeast supplemented diet for 21 days $(p=0.001), 35$ days $(\mathrm{p}=0.038)$ and 42 days $(p<0.001)$, while FC in studies where broiler chickens were placed on yeast supplemented diets for 28 days $(p=0.340)$ and 56 days $(\mathrm{p}=0.665)$ were not significant. Ross $(\mathrm{p}<0.001)$, Arbor acres $(\mathrm{p}<0.001)$ and Cobb $(\mathrm{p}<0.001)$ had significantly decreased FC, whilst other breeds were not significant ( $p>0.05)$. 
Studies

Oyedeji et al 2008 Al Mansour et al 201 Al Mansour et al 2011-2 Al Mansour et al 2011-3 Al Mansour et al 2011-4 Al Mansour et al 2011-5 Al Mansour et al 2011-6 Njeru 2013

Njeru 2013-2

El Fatah 1999

El Fatah 1999-2

El Fatah 1999-3

Mohammed et al 2015

Mohammed et al 2015-2

Mohammed et al 2015-3

Mohammed et al 2015-4

Mohammed et al 2015-5

Mohammed et al 2015-6

Chen et al 2017

Chen et al 2017-2

Aluwong et al 2012

Aluwong et al 2012-2

Osman 2006

Osman 2006-2

Osman 2006-3

Shareef \& Al-Dabbagh 2009

Shareef \& Al-Dabbagh 2009-2

Shareef \& Al-Dabbagh 2009-3

Shareef \& Al-Dabbagh 2009-4

Chand et al 2014

Chand et al 2014-2

Chand et al 2014-3

Manal 2012

Manal 2012-2

Manal 2012-3

Manal 2012-4

Manal 2012-5

Manal 2012-6

Buba et al 2016

Buba et al 2016-2

Buba et al 2016-3

Buba et al 2016-4

Buba et al 2016-5

Buba et al 2016-6

Buba et al 2016-7

Buba et al 2016-8

Atul Shankar et al 2017

Atul Shankar et al 2017-2

Atul Shankar et al 2017-3

Yalcin et al 2013

Yalcin et al 2013-2

Yalcin et al 2013-3

Yalcin et al 2013-4

Yalcin et al 2013-5

Yalcin et al 2013-6

Yalcin et al 2013-7

Yalcin et al 2013-8

Mohamed et al 2016

Mohamed et al 2016-2

Mohamed et al 2016-3

Priya \& Buba 2013

Priya \& Buba 2013-2

Overall (|^ $2=89.59 \%, P<0.001)-0.429(-0.606,-0.253)$
Estimate (95\% C.I.)

$-1.601(-2.104,-1.097)$

$-0.395(-0.756,-0.033)$

$-0.130(-0.488,0.228)$

$-0.261(-0.621,0.098)$

$0.558(0.193,0.923)$

$-1.412(-1.811,-1.012)$

$-0.714(-1.083,-0.344)$

$0.000(-0.438,0.438)$

$-0.404(-0.847,0.039)$

$0.692(0.171,1.213)$

$1.065(0.524,1.605)$

$0.499(-0.015,1.013)$

$-0.426(-0.869,0.017)$

$0.358(-0.084,0.800)$

$-0.105(-0.543,0.334)$

$0.219(-0.221,0.658)$

$0.433(-0.011,0.876)$

$0.796(0.341,1.251)$

$-2.147(-2.597,-1.698)$

$-1.159(-1.546,-0.772)$

$-0.165(-0.558,0.227)$

$-0.249(-0.643,0.144)$

$-1.185(-1.610,-0.760)$

$0.229(-0.164,0.622)$

$0.453(0.056,0.850)$

$-0.014(-0.634,0.605)$

$-0.022(-0.641,0.598)$

$-0.087(-0.707,0.533)$

$-0.167(-0.788,0.454)$

$-0.956(-1.490,-0.422)$

$-1.100(-1.643,-0.557)$

$-1.344(-1.904,-0.784)$

$0.385(-0.126,0.896)$

$-0.712(-1.234,-0.190)$

$-0.350(-0.860,0.160)$

$-0.620(-1.139,-0.102)$

$-0.879(-1.409,-0.349)$

$-0.493(-1.007,0.020)$

$-0.180 \quad(-0.569,0.208)$

$-0.411(-0.803,-0.018)$

$0.265(-0.125,0.654)$

$0.437(0.044,0.830)$

$-0.783(-1.186,-0.380)$

$-0.919(-1.327,-0.511)$

$-0.084(-0.472,0.304)$

$1.031(0.618,1.444)$

$-0.358(-0.687,-0.029)$

$-0.675(-1.011,-0.339)$

$-0.946(-1.291,-0.602)$

$-1.265(-1.779,-0.752)$

$-1.400(-1.923,-0.877)$

$-1.674(-2.219,-1.130)$

$-1.066(-1.567,-0.565)$

$-0.463(-0.937,0.012)$

$-0.641(-1.122,-0.161)$

$-1.071(-1.572,-0.570)$

$-0.463(-0.937,0.012)$

$-0.560(-1.177,0.056)$

$-0.560(-1.177,0.056)$

$0.000(-0.605,0.605)$

$-1.882(-2.352,-1.411)$

$-1.665(-2.120,-1.210)$
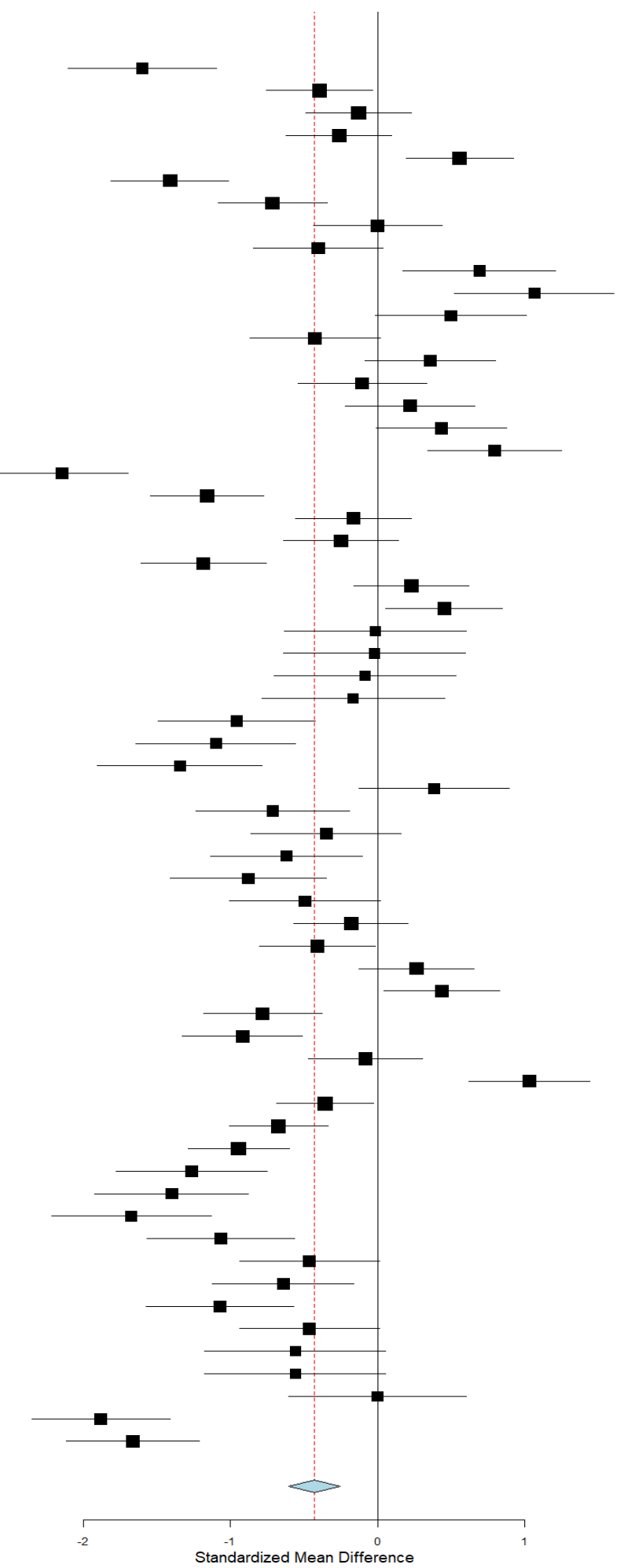

Figure 2. Forest plot of the effect of yeast supplementation on feed consumption in broiler chickens. The points to the right of the no effect line shows an increase in the outcome of interest, and the opposite depicts the reverse. The effect size is represented by individual square in the forest plot, while the upper and lower 95\% CI for the effect size are the line that joined the square 
Cumulative Studies

El Fatah 1999

+ El Fatah 1999-2

+ El Fatah 1999-3

+ Osman 2006

+ Osman 2006-2

Oyedeji et al 2008

Shareef \& Al-Dabbagh 2009

Shareef \& Al-Dabbagh 2009-2

+ Shareef \& Al-Dabbagh 2009-3

+ Shareef \& Al-Dabbagh 2009-4

+ Al Mansour et al 2011

+ Al Mansour et al 2011-2

- Al Mansour et al 2011-3

- Al Mansour et al 2011-5

+ Al Mansour et al 2011-5

+ Aluwong et al 2012

+ Aluwong et al 2012-2

+ Manal 2012

+ Manal 2012-2

+ Manal 2012-3

+ Manal 2012-4

+ Manal 2012-5

+ Manal 2012-6

+ Njeru 2013

+ Njeru 2013-2

+ Yalcin et al 2013

Yalcin et al 2013-2

Yalcin et al 2013-3

Yalcin et al 2013-4

Yalcin et al 2013-5

Yalcin et al 2013-6

+ Yalcin et al 2013-7

Yalcin et al 2013-8

+ Priya \& Buba 2013

+ Priya \& Buba 2013-2

+ Chand et al 2014

+ Chand et al 2014-2

+ Chand et al 2014-3

+ Mohammed et al 2015

+ Mohammed et al 2015-2

+ Mohammed et al 2015-3

Mohammed et al 2015-4

Mohammed et al 2015-5

Mohammed et al 2015-

Mohamed et al 2016-2

+ Mohamed et al 2016-3

+ Buba et al 2016

Buba et al 2016-2

Buba et al 2016-3

Buba et al 2016-4

Buba et al 2016-5

Buba et al 2016-6

+ Buba et al 2016-7

Buba et al 2016-8

+ Atul Shankar et al 2017

Atul Shankar et al 2017-2

- Atul Shankar et al 2017-3

+ Chen et al 2017

+ Chen et al 2017-2
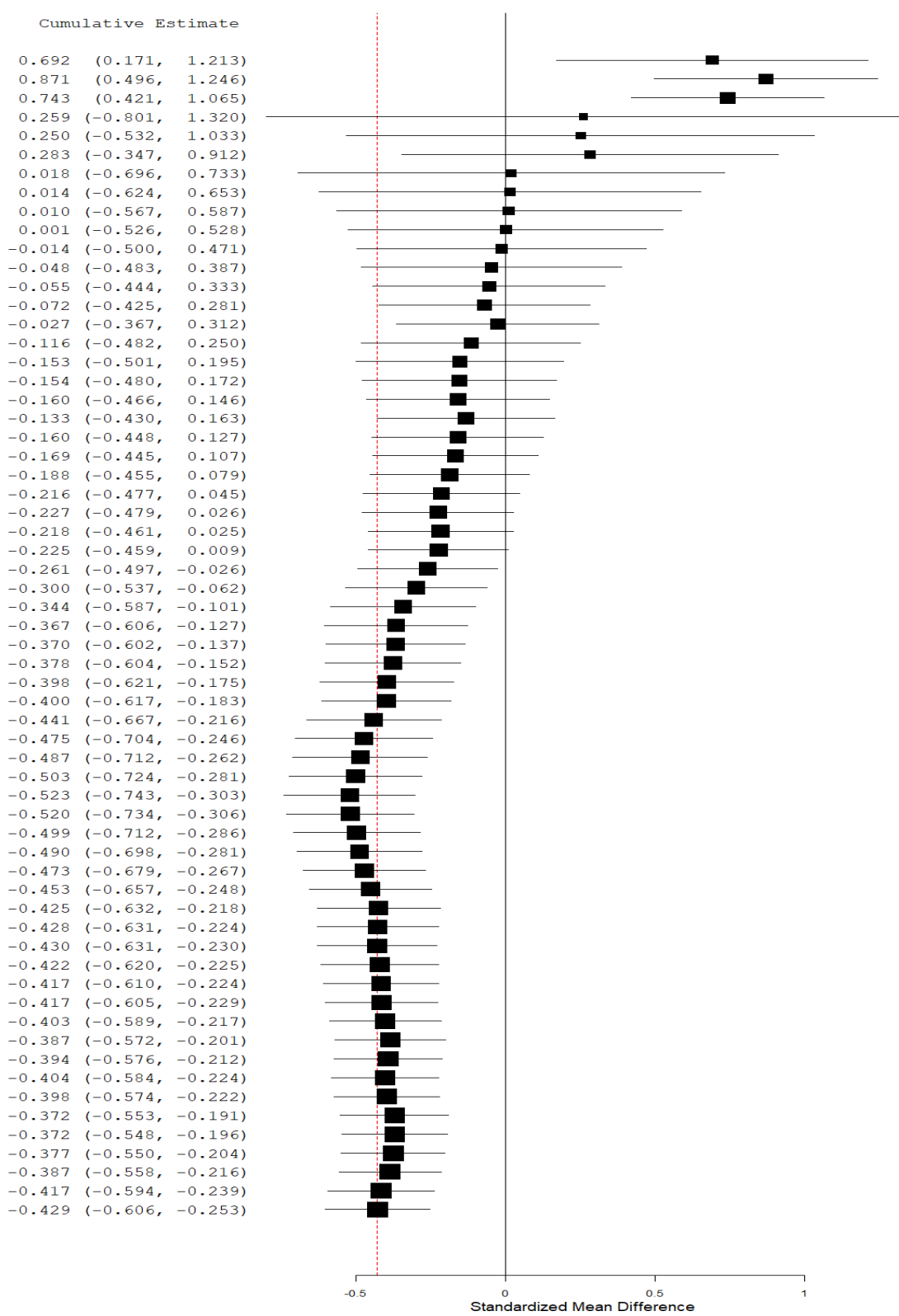

Figure 3. Trends of FC in broilers fed yeast supplemented diets

\section{Feed conversion ratio (FCR)}

The results of pooled effects estimation found a positive association between yeast supplementation and FCR in broiler chickens $(d=-0.354,95 \% \mathrm{CI}$ : -0.517 to -0.190 , $I^{2}=87.27 \%, \mathrm{p}<0.001$; Fig. 4). The temporal trends on the effect patterns of yeast supplementation on FCR in broiler chickens are shown in Figure 5. The results of the stratified analysis found an association between modifier variables and FCR in broiler chickens on yeast diet as presented in Table 3. Results of the stratified subgroup analysis revealed that FCR was positively influenced by the explanatory variables (study continent, $\mathrm{p}<0.001$; study country, $\mathrm{p}<0.0001$; duration of supplementation, $\mathrm{p}<0.001$; supplementation level, $\mathrm{p}<0.001$; broiler breed used, $\mathrm{p}<0.001$ ) when subgroup with one or two effect size(s) were removed from the analysis. Birds from 
studies undertaken in Europe $(p<0.001)$ and Asia $(\mathrm{p}<0.001)$ had superior FCR compared to chickens from studies performed in Africa $(p=0.296)$. Stratified analysis results indicate that the FCR for studies performed in Pakistan, Egypt, Indian and Turkey differed significantly $(\mathrm{p}<0.001)$. There was a correlation between FCR and duration of supplementation ( 21 days, $\mathrm{p}=0.002 ; 35$ days, $\mathrm{p}<0.001 ; 42$ days, $\mathrm{p}=0.038$ ), whereas no correlation exists between the FCR and the duration of supplementation ( 28 days, $p=0.340 ; 56$ days, $\mathrm{p}=0.665$ ). Broiler chickens fed yeast supplemented diet at a level of $>10 \mathrm{~g} / \mathrm{kg}$ feed $(\mathrm{p}=0.111)$ and $10 \mathrm{~g} / \mathrm{kg}$ feed $(\mathrm{p}=0.113)$ had poor FCR, whilst those that received yeast supplemented diet at a level of $<10 \mathrm{~g} / \mathrm{kg}$ feed $(p<0.001)$ had improved FCR. Ross $(p=0.001)$, Arbor acres $(p=0.003)$ and Cobb $(\mathrm{p}<0.001)$ had significantly improved FCR relative to Hubbard $(\mathrm{p}=0.354)$, Lohman $(p=0.742)$, Faobrow CD $(p=0.648)$ and White Rose $(\mathrm{p}=0.718)$.

Table 2. Relationship between moderators and FC in broiler chickens on yeast-based diets

\begin{tabular}{|c|c|c|c|c|c|}
\hline Subgroups & $\mathbf{n}$ & $d$ & $95 \% \mathrm{CI})$ & $I^{2}(\%)$ & $p$-value \\
\hline Study continent & 62 & -0.429 & -0.606 to -0.253 & 88.59 & $<0.001$ \\
\hline Africa & 34 & -0.109 & -0.313 to 0.095 & 85.61 & 0.296 \\
\hline Asia & 20 & -0.747 & -1.052 to -0.443 & 90.14 & $<0.001$ \\
\hline Europe & 8 & -0.993 & -1.301 to -0.685 & 66.94 & $<0.001$ \\
\hline Study country & 58 & -0.394 & -0.571 to -0.217 & 88.80 & $<0.001$ \\
\hline Nigeria & 11 & -0.235 & -0.662 to 0.152 & 90.09 & 0.233 \\
\hline Saudi Arabia & 6 & -0.389 & -0.894 to 0.116 & 91.12 & 0.131 \\
\hline Sudan & 15 & 0.131 & -0.172 to 0.434 & 83.64 & 0.395 \\
\hline Iraq & 4 & -0.072 & -0.382 to 0.238 & 0.00 & 0.648 \\
\hline Pakistan & 3 & -1.127 & -1.442 to -0.812 & 0.00 & $<0.001$ \\
\hline Egypt & 6 & -0.442 & -0.800 to -0.084 & 65.12 & $<0.001$ \\
\hline India & 5 & -1.086 & -1.618 to -0.554 & 89.88 & $<0.001$ \\
\hline Turkey & 8 & -0.993 & -1.301 to -0.685 & 88.80 & $<0.001$ \\
\hline DS (days) & 60 & -0.384 & -0.555 to -0.213 & 88.25 & $<0.001$ \\
\hline 21 & 19 & -0.499 & -0.808 to -0.191 & 87.41 & $<0.001$ \\
\hline 28 & 8 & -0.239 & -0.731 to 0.253 & 91.43 & 0.340 \\
\hline 35 & 4 & -1.140 & -1.384 to -0.896 & 0.00 & 0.038 \\
\hline 42 & 25 & -0.260 & -0.506 to -0.015 & 86.78 & $<0.001$ \\
\hline 56 & 4 & -0.189 & -1.047 to 0.669 & 94.49 & 0.665 \\
\hline $\mathrm{SL}$ (g/kg feed) & 62 & -0.429 & -0.606 to -0.253 & 89.59 & $<0.001$ \\
\hline$<10$ & 39 & -0.684 & -0.882 to -0.485 & 87.17 & $<0.001$ \\
\hline$>10$ & 16 & 0.218 & -0.051 to 0.487 & 81.94 & 0.054 \\
\hline 10 & 7 & -0.473 & -0.955 to 0.008 & 86.56 & 0.113 \\
\hline Broiler breed used & 60 & -0.437 & -0.620 to -0.254 & 89.90 & $<0.001$ \\
\hline Ross & 23 & -0.626 & -0.952 to -0.300 & 91.20 & $<0.001$ \\
\hline Arbor Acres & 10 & -0.642 & -1.084 to -0.201 & 83.32 & $<0.001$ \\
\hline Hubbard & 9 & -0.221 & -0.689 to -0.246 & 88.63 & 0.354 \\
\hline Lohman & 3 & -0.165 & -1.144 to -0.815 & 94.31 & 0.742 \\
\hline Faobrow CD & 4 & -0.072 & -0.382 to 0.238 & 0.00 & 0.648 \\
\hline White Rose & 8 & -0.081 & -0.519 to 0.358 & 89.76 & 0.718 \\
\hline Cobb & 3 & -0.657 & -0.990 to -0.323 & 66.02 & $<0.001$ \\
\hline
\end{tabular}

$\mathrm{n}$ - number of effect sizes; d - Hedges' d, CI - confidence interval, $\mathrm{I}^{2}$ - heterogeneity 
Studies

Oyedeji et al 2008 Al Mansour et al 2011

Al Mansour et al 2011-2

Al Mansour et al 2011-3

Al Mansour et al 2011-4

Al Mansour et al 2011-5

Al Mansour et al 2011-6

Njeru 2013

Njeru 2013-2

El Fatah 1999

El Fatah 1999-2

El Fatah 1999-3

Mohammed et al 2015

Mohammed et al 2015-2

Mohammed et al 2015-3

Mohammed et al 2015-4

Mohammed et al 2015-5

Mohammed et al 2015-6

Chen et al 2017

Aluwong et al 2012

Aluwong et al 2012-2

Osman 2006

Osman 2006-2

Osman 2006-3

Shareef \& Al-Dabbagh 2009

Shareef \& Al-Dabbagh 2009-2

Shareef \& Al-Dabbagh 2009-3

Shareef \& Al-Dabbagh 2009-4

Chand et al 2014

Chand et al 2014-2

Chand et al 2014-3

Manal 2012

Manal 2012-2

Manal 2012-3

Manal 2012-4

Manal 2012-5

Manal 2012-6

Buba et al 2016

Buba et al 2016-2

Buba et al 2016-3

Buba et al 2016-4

Buba et al 2016-5

Buba et al 2016-6

Buba et al 2016- 7

Buba et al 2016-8

Atul Shankar et al 2017

Atul Shankar et al 2017-2

Atul Shankar et al 2017-3

Yal??n et al 2013

Yalcin et al 2013

Yalcin et al 2013-2

Yalcin et al 2013-3

Yalcin et al 2013-4

Yalcin et al 2013-5

Yalcin et al 2013-6

Yalcin et al 2013-7

Mohamed et al 2016

Mohamed et al 2016-2

Mohamed et al 2016-3

Overall $\left(I^{\wedge} 2=87.27 \%, P<0.001\right)$

Estimate (95\% C.I.)

$-1.601 \quad(-2.104,-1.097)$

$-0.395(-0.756,-0.033)$

$-0.130(-0.488,0.228)$

$-0.261(-0.621,0.098)$

$0.558(0.193,0.923)$

$-1.412(-1.811,-1.012)$

$-0.714(-1.083,-0.344)$

$0.000(-0.438,0.438)$

$-0.404 \quad(-0.847,0.039)$

$0.692(0.171,1.213)$

$1.065(0.524,1.605)$

$0.499(-0.015,1.013)$

$-0.426(-0.869,0.017)$

$0.358(-0.084,0.800)$

$-0.105(-0.543,0.334)$

$0.219(-0.221, \quad 0.658)$

$0.433(-0.011,0.876)$

$0.796(0.341,1.251)$

$-1.159(-1.546,-0.772)$

$-0.165(-0.558,0.227)$

$-0.249(-0.643,0.144)$

$-1.185(-1.610,-0.760)$

$0.229(-0.164,0.622)$

$0.453(0.056,0.850)$

$-0.014 \quad(-0.634,0.605)$

$-0.022(-0.641,0.598)$

$-0.087(-0.707,0.533)$

$-0.167(-0.788,0.454)$

$-0.956(-1.490,-0.422)$

$-1.100(-1.643,-0.557)$

$-1.344(-1.904,-0.784)$

$0.385(-0.126,0.896)$

$-0.712(-1.234,-0.190)$

$-0.350(-0.860,0.160)$

$-0.620(-1.139,-0.102)$

$-0.879(-1.409,-0.349)$

$0.493(-1.007,0.020)$

$-0.180(-0.569,0.208)$

$-0.411(-0.803,-0.018)$

$0.265(-0.125,0.654)$

$0.437 \quad(0.044,0.830)$

$-0.783(-1.186,-0.380)$

$-0.919(-1.327,-0.511)$

$-0.084(-0.472,0.304)$

$1.031(0.618,1.444)$

$-0.358(-0.687,-0.029)$

$-0.675(-1.011,-0.339)$

$-0.946(-1.291,-0.602)$

$-1.265(-1.779,-0.752)$

$-1.400(-1.923,-0.877)$

$-1.674(-2.219,-1.130)$

$-1.066(-1.567,-0.565)$

$-0.463(-0.937,0.012)$

$\begin{array}{rrr}-0.463 & (-0.937, & 0.012) \\ -0.641 & (-1.122,-0.161)\end{array}$

$-1.071(-1.572,-0.570)$

$-0.463(-0.937,0.012)$

$-0.560(-1.177,0.056)$

$-0.560(-1.177,0.056)$

$0.000(-0.605,0.605)$

$-0.354(-0.517,-0.190)$

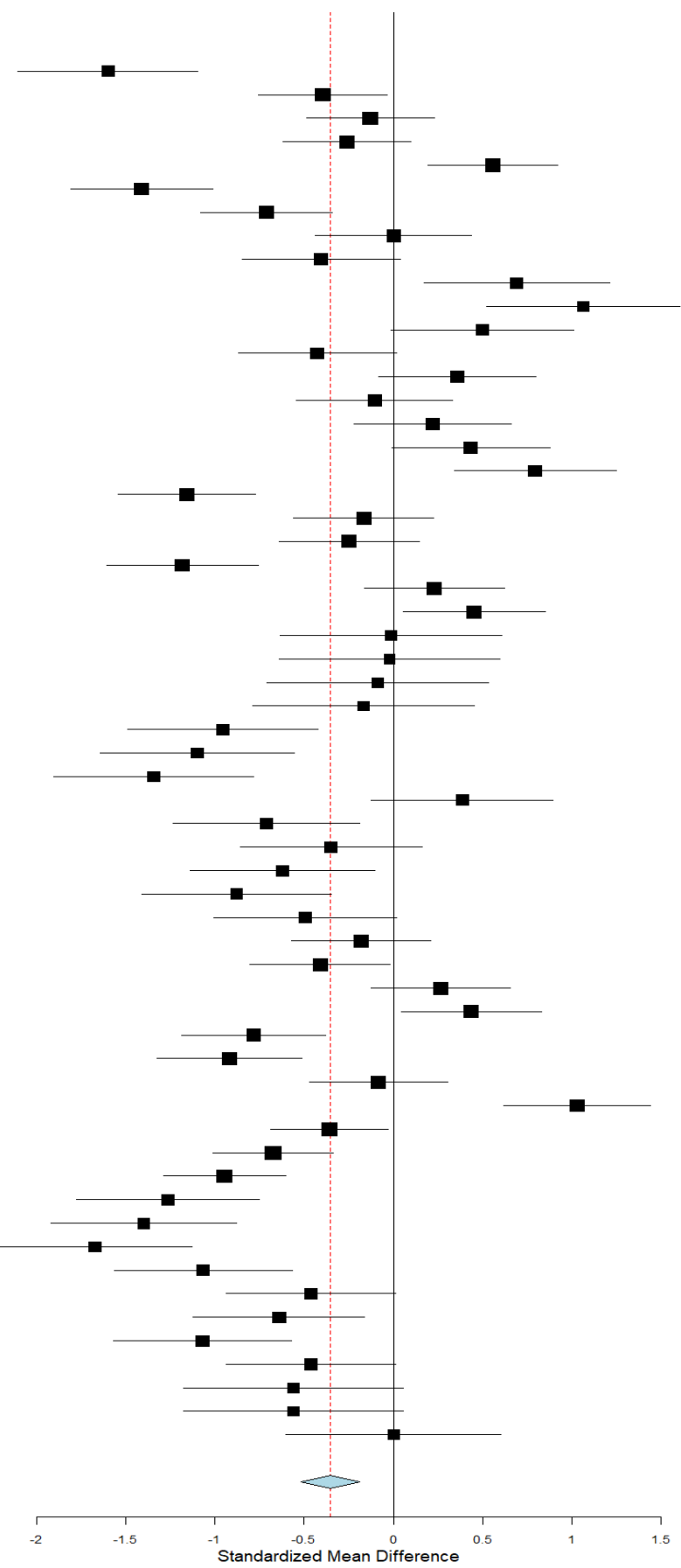

Figure 4. Effect of probiotic-yeast supplementation on FCR of broiler chickens

\section{Body weight gain (BWG)}

BWG was statistically increased from zero $(d=0.310,95 \%$ CI: 0.130 to 0.491 , $I^{2}=87.13 \%, \mathrm{p}<0.001$; Fig. 6). The impact of yeast on BWG in broiler chickens in chronological order are shown in Figure 7. The results of the stratified subgroup analysis of the association between the explanatory variables and the BWG in broiler chickens are presented in Table 4. The mean effects estimate for the meta-analysis were $0.310,0.325,0.329,0.310$ and 0.310 for study continent $(\mathrm{p}<0.001)$, study 
country $(\mathrm{p}=0.001)$, duration of supplementation $(\mathrm{p}<0.001)$, supplementation level $(\mathrm{p}<0.001)$ and broiler breed used $(p<0.001)$, respectively, when the analysis was stratified. When the BWG analysis was disaggregated by study continent, studies conducted in Asia $(p<0.001)$ and Europe $(p<0.001)$ had improved BWG compared to those conducted in Africa. The results of BWG disaggregated by study country revealed that studies conducted in Iraq $(p=0.015)$, India $(p=0.019)$ and Turkey ( $p<0.001)$ had statistically increased BWG following the removal of studies conducted in Saudi Arabia, Kenya and Taiwan that had less than 3 effect sizes. Studies conducted in Egypt, Sudan and Nigeria had similar values (Egypt: $p=0.556$, Sudan: $p=0.728$, Nigeria: $p=0.172$ ). Broiler chickens from experiments that received yeast supplemented diets for 21 days $(\mathrm{p}<0.001)$ had increased BWG, while those that received yeast supplemented diets for 42 days $(p=0.125)$ and 56 days $(p=0.983)$ were not significant. Studies that fed yeast for 35 days were removed from the analysis because they had less than 3 effect sizes. There was a significant positive association between BWG, and yeast supplementation level $(<10 \mathrm{~g} / \mathrm{kg}$ feed, $p<0.001$ ), whereas there was no significant association between BWG, and supplementation level $(10 \mathrm{~g} / \mathrm{kg}$ feed, $\mathrm{p}=0.135 ;>10 \mathrm{~g} / \mathrm{kg}$ feed, $\mathrm{p}=0.349)$. When BWG was disaggregated by breed of broiler used, Ross $(p=0.001)$, Faobrow CD $(\mathrm{p}=0.015)$ and Cobb $(\mathrm{p}<0.019)$ had significantly improved BWG.
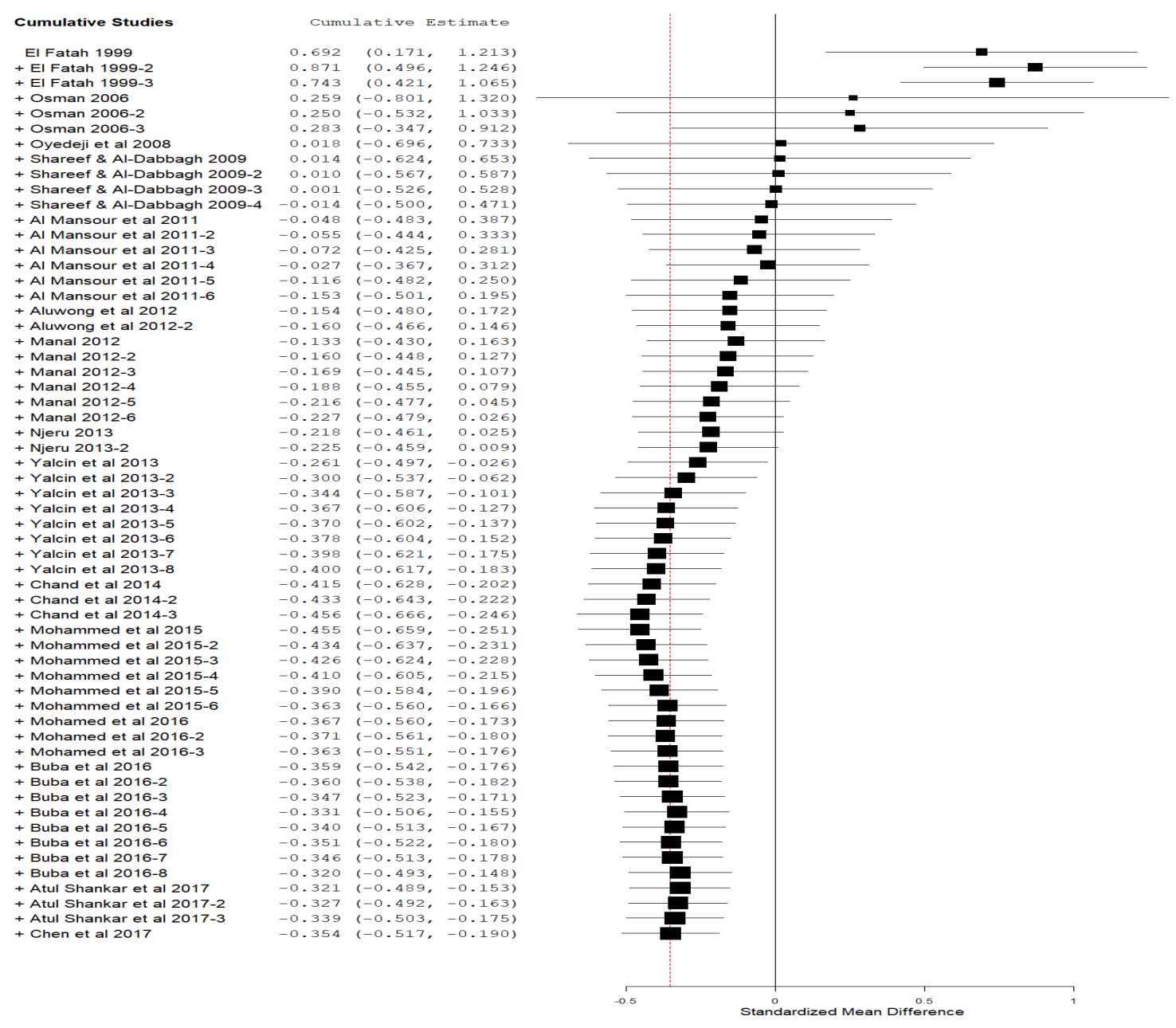

Figure 5. Trends of FCR in broilers fed yeast supplemented diets 
Table 3. Association between moderators and FCR in broilers on yeast-based diets

\begin{tabular}{|c|c|c|c|c|c|}
\hline Subgroups & n & $d$ & $95 \% \mathrm{CI})$ & $I^{2}(\%)$ & $p$-value \\
\hline Study continent & 59 & -0.354 & -0.517 to -0.190 & 87.27 & $<0.001$ \\
\hline Africa & 34 & -0.109 & -0.313 to 0.095 & 85.61 & 0.296 \\
\hline Asia & 17 & -0.545 & -0.806 to -0.285 & 84.32 & $<0.001$ \\
\hline Europe & 8 & -0.993 & -1.301 to -0.685 & 66.94 & $<0.001$ \\
\hline Study country & 56 & -0.344 & -0.513 to -0.175 & 87.37 & $<0.001$ \\
\hline Nigeria & 11 & -0.235 & -0.662 to 0.152 & 90.09 & 0.233 \\
\hline Saudi Arabia & 6 & -0.389 & -0.894 to 0.116 & 91.12 & 0.131 \\
\hline Sudan & 15 & 0.131 & -0.172 to 0.434 & 83.64 & 0.395 \\
\hline Iraq & 4 & -0.072 & -0.382 to 0.238 & 0.00 & 0.648 \\
\hline Pakistan & 3 & -1.127 & -1.442 to -0.812 & 0.00 & $<0.001$ \\
\hline Egypt & 6 & -0.442 & -0.800 to -0.084 & 65.12 & $<0.015$ \\
\hline India & 3 & -0.657 & -0.990 to -0.323 & 66.02 & $<0.001$ \\
\hline Turkey & 8 & -0.993 & -1.301 to -0.685 & 88.80 & $<0.001$ \\
\hline DYS (days) & 59 & -0.354 & -0.517 to -0.190 & 88.27 & $<0.001$ \\
\hline 21 & 18 & -0.404 & -0.659 to -0.149 & 80.36 & 0.002 \\
\hline 28 & 8 & -0.239 & -0.731 to 0.253 & 91.43 & 0.340 \\
\hline 35 & 4 & -1.140 & -1.384 to -0.896 & 0.00 & $<0.001$ \\
\hline 42 & 25 & -0.260 & -0.506 to -0.015 & 86.78 & 0.038 \\
\hline 56 & 4 & -0.189 & -1.047 to 0.669 & 94.49 & 0.665 \\
\hline YSL (g/kg feed) & 59 & -0.354 & -0.517 to -0.190 & 87.27 & $<0.001$ \\
\hline$<10$ & 37 & -0.610 & -0.791 to -0.429 & 83.78 & $<0.001$ \\
\hline$>10$ & 16 & 0.218 & -0.051 to 0.487 & 81.94 & 0.111 \\
\hline 10 & 6 & -0.284 & -0.633 to 0.065 & 69.57 & 0.113 \\
\hline Breeds of broiler used & 57 & -0.359 & -0.529 to -0.189 & 87.68 & $<0.001$ \\
\hline Ross & 21 & -0.516 & -0.833 to -0.199 & 89.77 & 0.01 \\
\hline Arbor Acres & 9 & -0.474 & -0.790 to -0.159 & 74.20 & 0.003 \\
\hline Hubbard & 9 & -0.221 & -0.689 to -0.246 & 88.63 & 0.354 \\
\hline Lohman & 3 & -0.165 & -1.144 to -0.815 & 94.31 & 0.742 \\
\hline Faobrow CD & 4 & -0.072 & -0.382 to 0.238 & 0.00 & 0.648 \\
\hline White Rose & 8 & -0.081 & -0.519 to 0.358 & 89.76 & 0.718 \\
\hline Cobb & 3 & -0.657 & -0.990 to -0.323 & 66.02 & $<0.001$ \\
\hline
\end{tabular}

\section{Analysis of heterogeneity and moderators}

Data in Table 5 presents the mixed effects meta-regression of the impact of yeast supplementation in broiler chicken performance. Forest plots of the 16 studies comprising 62 comparisons that evaluated the effect of yeast on FC in broilers provided evidence of significant heterogeneity $\left(I^{2}\right.$-statistic $=89.59 \%, 95 \% \mathrm{CI}:-0.606$ to -0.253 , $\mathrm{p}<0.001$, Fig. 2) and sensitivity analysis was not able to resolve the problem heterogeneity. Subgroup analysis did not remove the challenges of large heterogeneity among the studies included in the meta-analysis. Thus, the substantial heterogeneity continues, suggesting that these analyses cannot fix the problem of heterogeneity. Metaregression, revealed that study continent $\left(\mathrm{Q}_{\mathrm{B}}=19.9\right.$, degree of freedom, $\mathrm{df}=2$, $\mathrm{p}<0.001)$, study country $\left(\mathrm{Q}_{\text {в }}=44.87\right.$, $\left.\mathrm{df}=9, \mathrm{p}<0.001\right)$, duration of supplementation 
$\left(\mathrm{Q}_{\mathrm{B}}=15.5, \mathrm{df}=5, \mathrm{p}=0.0084\right)$ and supplementation level $\left(\mathrm{Q}_{\mathrm{B}}=23.8, \mathrm{df}=2, \mathrm{p}<0.001\right)$ accounted for most the heterogeneity. Heterogeneity existed amongst the articles utilized in the analysis (FCR; $I^{2}=87.27 \%, 95 \%$ CI: -0.517 to $-0.190, p<0.001$, Fig. 4 and BWG; $I^{2}=87.13 \%$, 95\% CI: 0.130 to $0.491, p<0.001$, Fig. 6). Mixed effect metaregression analysis revealed that study continent and yeast supplementation level were predictors of the study effect observed on FCR, whereas study continent, study country, supplementation level and broiler breed were predictors of study effects noticed on BWG results.

Table 4. Relationship between moderators and BWG in broilers on yeast-based diets

\begin{tabular}{c|c|c|c|c|c}
\hline Subgroups & $\mathbf{n}$ & $\boldsymbol{d}$ & $\mathbf{9 5 \%} \mathbf{C I})$ & $\boldsymbol{\boldsymbol { I } ^ { \mathbf { 2 } } \mathbf { ( \% ) }}$ & $\boldsymbol{p}$-value \\
\hline Study continent & 49 & 0.310 & 0.133 to 0.487 & 86.51 & $<0.001$ \\
Africa & 31 & 0.167 & -0.067 to 0.401 & 87.63 & 0.163 \\
Asia & 10 & 0.335 & 0.054 to 0.615 & 77.12 & 0.019 \\
Europe & 8 & 0.838 & 0.512 to 1.164 & 71.35 & $<0.001$ \\
Study country & 44 & 0.325 & 0.130 to 0.520 & 71.35 & 0.001 \\
Nigeria & 8 & 0.307 & -0.314 to 0.748 & 89.49 & 0.172 \\
Sudan & 15 & 0.068 & -0.315 to 0.451 & 89.76 & 0.728 \\
Iraq & 4 & 0.389 & 0.075 to 0.703 & 0.00 & 0.015 \\
Egypt & 6 & 0.147 & -0.343 to 0.637 & 81.49 & 0.556 \\
India & 3 & 0.549 & 0.089 to 1.009 & 82.33 & $<0.019$ \\
Turkey & 8 & 0.838 & 0.512 to 1.164 & 71.35 & $<0.001$ \\
DS (days) & 48 & 0.329 & 0.147 to 0.510 & 86.36 & $<0.001$ \\
21 & 17 & 0.555 & 0.243 to 0.867 & 83.62 & 0.003 \\
28 & 8 & 0.322 & -0.176 to 0.819 & 91.58 & 0.205 \\
42 & 20 & 0.208 & -0.058 to 0.473 & 84.73 & 0.125 \\
56 & 3 & -0.007 & -0.673 to 0.658 & 88.34 & 0.983 \\
SL (g/kg feed) & 49 & 0.310 & 0.133 to 0.487 & 86.51 & $<0.001$ \\
<10 & 31 & 0.470 & 0.271 to -0.669 & 83.72 & $<0.001$ \\
$>10$ & 14 & -0.134 & -0.413 to 0.146 & 80.11 & 0.349 \\
10 & 4 & 0.573 & -0.179 to 1.325 & 89.79 & 0.135 \\
Broiler breed used & 49 & 0.310 & 0.133 to 0.487 & 86.51 & $<0.001$ \\
Ross & 16 & 0.651 & 0.342 to 0.960 & 83.53 & 0.001 \\
Arbor Acres & 10 & 0.145 & -0.174 to 0.464 & 79.08 & 0.374 \\
Hubbard & 6 & -0.173 & -0.758 to 0.412 & 90.07 & 0.563 \\
Lohman & 3 & 0.027 & -0.933 to 0.988 & 94.11 & 0.956 \\
Faobrow CD & 4 & 0.389 & 0.075 to 0.703 & 0.00 & 0.015 \\
White Rose & 7 & 0.182 & -0.249 to 0.612 & 87.93 & 0.408 \\
Cobb & 3 & 0.549 & 0.089 to 1.009 & 88.51 & 0.019 \\
\hline & & & & &
\end{tabular}

\section{Analysis of publication bias}

The results of the funnel plot of the impact of yeast supplementation on the productivity of broiler chickens as shown in Figure $8 A-C$ revealed that the plots were asymmetrical. However, the Rosenberg fail-safe number of 3138 (FC), 1913 (FCR) and 964 (BWG) which is more than 9, 6 and 4-folds, respectively above the threshold of 320 
$(5 \times 62+10), 305(5 \times 59+10)$ and $255(5 \times 49+10)$ is required to declare the mean effect size robust. Consequently, the existence of publication bias was not a problem in this study as comparatively large number of unpublished studies would be needed to alter the statistically significant effects.

\begin{tabular}{|c|c|c|c|}
\hline Studies & Est & imate 195 & 응 C.I.) \\
\hline Oyedeji et al 2008 & 1.223 & $(0.746$, & $1.701)$ \\
\hline Al Mansour et al 2011 & 0.369 & $(0.008$, & $0.730)$ \\
\hline Njeru 2013 & 0.402 & $(-0.041$, & $0.845)$ \\
\hline Njeru 2013-2 & 0.393 & $(-0.049$, & $0.836)$ \\
\hline El Fatah 1999 & -0.622 & $(-1.140$ & $-0.104)$ \\
\hline El Fatah 1999-2 & -0.314 & $(-0.823$, & $0.196)$ \\
\hline El Fatah 1999-3 & -0.213 & $(-0.720$, & $0.295)$ \\
\hline El Fatah 1999-4 & 1.295 & (0.738, & $1.852)$ \\
\hline Mohammed et al 2015 & 1.371 & 10.884, & $1.858)$ \\
\hline Mohammed et al 2015-2 & -0.541 & $(-0.988$, & $-0.095)$ \\
\hline Mohammed et al 2015-3 & -0.236 & $(-0.676$ & $0.203)$ \\
\hline Mohammed et al 2015-4 & -0.304 & $(-0.745$, & $0.137)$ \\
\hline Mohammed et al 2015-5 & -0.560 & $(-1.007$ & $-0.113)$ \\
\hline Mohammed et al 2015-6 & -0.738 & $(-1.191$, & $-0.286)$ \\
\hline Chen et al 2017 & -0.516 & $(-0.880$ & $-0.152)$ \\
\hline Chen et al 2017-2 & 0.320 & $(-0.040$, & $0.680)$ \\
\hline Osman 2006 & 1.011 & (0.595, & $1.428)$ \\
\hline Osman 2006-2 & -0.318 & $(-0.713$, & $0.076)$ \\
\hline Osman 2006-3 & -0.606 & $(-1.007$ & $-0.205)$ \\
\hline Shareef \& Al-Dabbagh 2009 & 0.034 & $(-0.586$, & $0.654)$ \\
\hline Shareef \& Al-Dabbagh 2009-2 & 0.276 & $(-0.346$ & $0.899)$ \\
\hline Shareef \& Al-Dabbagh 2009-3 & 0.551 & $(-0.080$, & $1.183)$ \\
\hline Shareef \& Al-Dabbagh 2009-4 & 0.718 & (0.078, & 1.357) \\
\hline Manal 2012 & 0.409 & $(-0.103$, & $0.920)$ \\
\hline Manal 2012-2 & 0.922 & (0.390, & 1.454) \\
\hline Manal 2012-3 & -0.234 & $(-0.742$, & $0.274)$ \\
\hline Manal 2012-4 & 0.224 & $(-0.284$, & $0.731)$ \\
\hline Manal 2012-5 & 0.440 & $(-0.072$, & $0.952)$ \\
\hline Manal 2012-6 & -0.878 & $(-1.407$, & $-0.348)$ \\
\hline Buba et al 2016 & 0.782 & 10.379, & $1.185)$ \\
\hline Buba et al 2016-2 & 0.936 & (0.527, & $1.345)$ \\
\hline Buba et al $2016-3$ & -0.343 & $(-0.734$, & $0.048)$ \\
\hline Buba et al 2016-4 & -0.069 & $(-0.457$, & $0.320)$ \\
\hline Buba et al 2016-5 & 0.425 & 10.032, & $0.817)$ \\
\hline Buba et al 2016-6 & 0.234 & $(-0.156$, & $0.623)$ \\
\hline Buba et al 2016-7 & -0.684 & $(-1.083$, & $-0.285)$ \\
\hline Atul Shankar et al 2017 & 0.149 & $(-0.178$, & $0.476)$ \\
\hline Atul Shankar et al 2017-2 & 0.541 & $(0.208$, & $0.874)$ \\
\hline Atul Shankar et al 2017-3 & 0.965 & 10.620, & $1.310)$ \\
\hline Yalcin et al 2013 & 1.267 & (0.754, & $1.781)$ \\
\hline Yalcin et al 2013-2 & 1.282 & $(0.767$, & $1.796)$ \\
\hline Yalcin et al 2013-3 & 1.512 & (0.981, & $2.043)$ \\
\hline Yalcin et al 2013-4 & 0.847 & 10.358, & $1.336)$ \\
\hline Yalcin et al 2013-5 & 0.391 & $(-0.082$, & $0.864)$ \\
\hline Yalcin et al 2013-6 & 0.511 & (0.035, & $0.987)$ \\
\hline Yalcin et al 2013-7 & 0.799 & (0.312, & $1.286)$ \\
\hline Yalcin et al 2013-8 & 0.181 & $(-0.289$, & $0.650)$ \\
\hline Mohamed et al 2016 & 1.128 & 10.477, & $1.779)$ \\
\hline Mohamed et al 2016-2 & 0.890 & 10.256, & $1.525)$ \\
\hline Overall (|^2=87.13\% & 0.310 & 10.130, & $0.491)$ \\
\hline
\end{tabular}

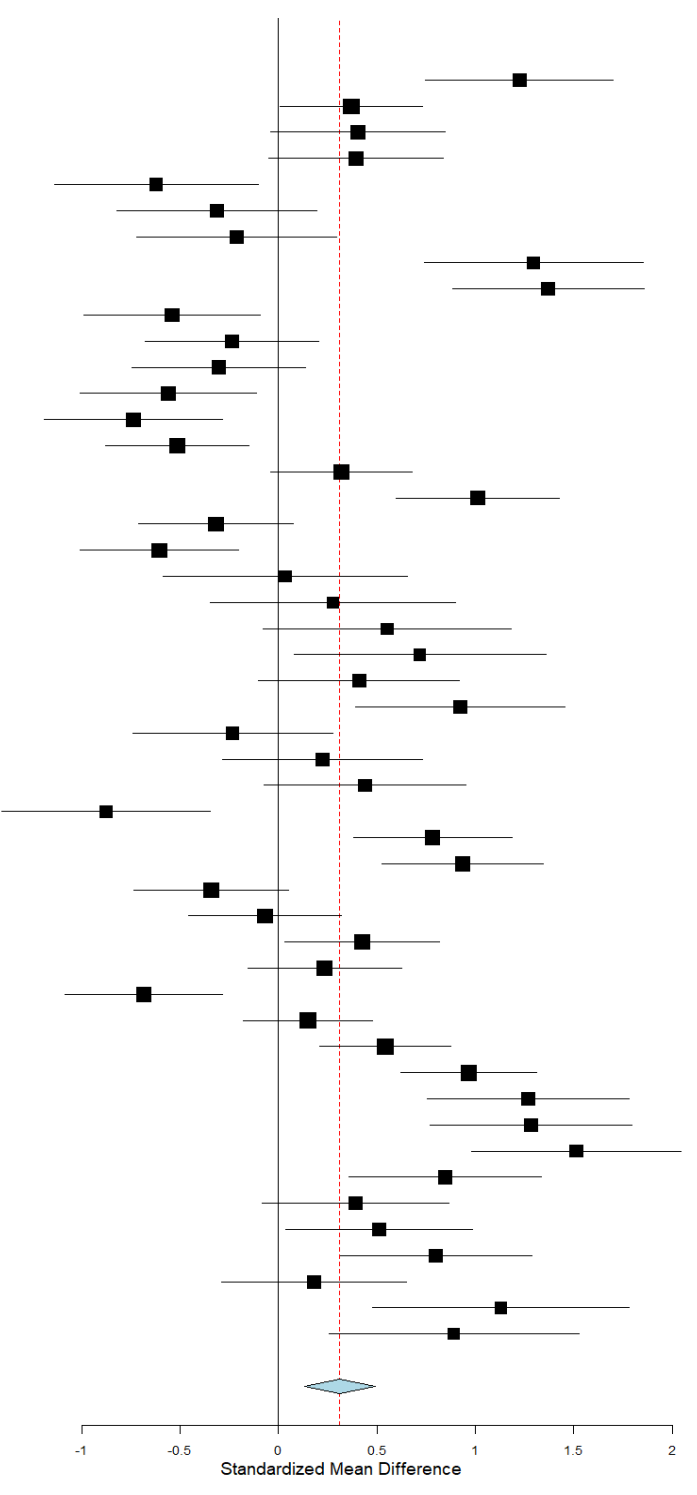

Figure 6. Forest plot of the effects probiotic (yeast) supplementation on BWG of broiler chickens

\section{Discussion}

\section{Probiotic effect}

In the last couple of years, the incorporation of small amounts of yeast in animal feed as a growth enhancing agent instead of antibiotics has received considerable attention (Ahmed et al., 2015; Gao et al., 2017; Ogbuewu et al., 2019). Basically, yeast is rich in essential nutrients and contains mannan oligosaccharides (MOS) that helps in the multiplication of beneficial microbes in the guts of broilers (Spring et al., 2000). The findings from the present meta-analysis of 16 RCTs representing 10 study countries 
drawn from three study continents indicated that broilers fed yeast supplemented diets had improved productive indices. This finding is consistent with the previous results of Hooge (2004) and Frizzo et al. (2011) who reported that probiotic (lactic acid bacteria) and actigen ${ }^{\circledR}$ (second-generation, yeast (Saccharomyces cerevisiae var. boulardii) cell wall product) supplementation improved BWG and FCR in broilers and calves, respectively. The enhanced FC, FCR and BWG recorded in the current meta-analysis could be partly ascribed to the direct nutritional effect of yeast that has been documented to increase productivity in broiler chickens (Hooge, 2004; Yalcin et al., 2013; Mohamed et al., 2016) and in calves (Frizzo et al., 2011). In addition, yeast has been recorded to improve the multiplication of helpful microbes in the intestines of chickens (Schneitz, 2005; Awad et al., 2006; Apata, 2008; Musa et al., 2009). It has also been documented that yeast activates the innate immune response of broilers (Haghighi et al., 2006; Apata, 2008; Musa et al., 2009); stimulates digestive enzyme production and activity (Yoon et al., 2004); and competes with pathogens for adhesion sites in the gut, thus preventing their multiplication in the intestine (Choudhari et al., 2008). The enhanced feed efficiency and the resultant increase in body weight gain is the ultimate result of probiotic intervention as reported by Bozkurt et al. (2009) in male broiler chickens fed MOS.

Cumulative Studies
El Fatah 1999
+ El Fatah 1999-2
+ El Fatah 1999-3
+ El Fatah 1999-4
+ Osman 2006
+ Osman 2006-2
+ Osman 2006-3
+ Oyedeji et al 2008
+ Shareef \& Al-Dabbagh 2009
+ Shareef \& Al-Dabbagh 2009-2
+ Shareef \& Al-Dabbagh 2009-3
+ Shareef \& Al-Dabbagh 2009-4
+ Al Mansour et al 2011
+ Manal 2012
+ Manal 2012-2
+ Manal 2012-3
+ Manal 2012-4
+ Manal 2012-5
+ Manal 2012-6
+ Njeru 2013
+ Njeru 2013-2
+ Yalcin et al 2013
+ Yalcin et al 2013-2
+ Yalcin et al 2013-3
+ Yalcin et al 2013-4
+ Yalcin et al 2013-5
+ Yalcin et al 2013-6
+ Yalcin et al 2013-7
+ Yalcin et al 2013-8
+ Mohammed et al 2015
+ Mohammed et al 2015-2
+ Mohammed et al 2015-3
+ Mohammed et al 2015-4
+ Mohammed et al 2015-5
+ Mohammed et al 2015-6
+ Buba et al 2016
+ Buba et al 2016-2
+ Buba et al 2016-3
+ Buba et al 2016-4
+ Buba et al 2016-5
+ Buba et al 2016-6
+ Buba et al 2016-7
+ Mohamed et al 2016
+ Mohamed et al 2016-2
+ Atul Shankar et al 2017
+ Atul Shankar et al 2017-2
+ Atul Shankar et al 2017-3
+ Chen et al 2017
+ Chen et al 2017-2

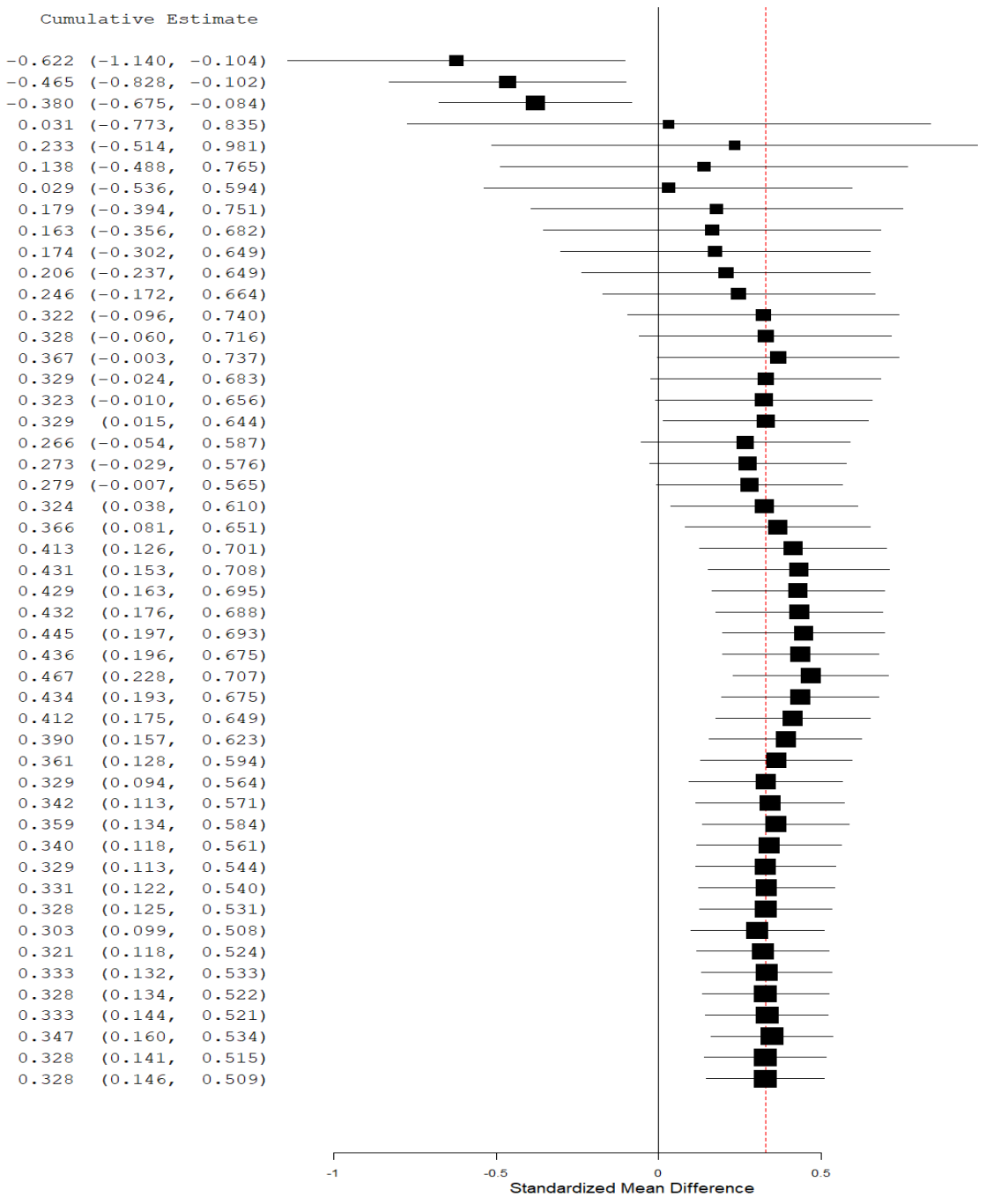

Figure 7. Trends of BWG in broilers fed yeast supplemented diets 
Table 5. Summary of the random weighted meta-analysis for the explanatory variables that act as a modifier on the effects of yeast supplementation on productivity of broiler chickens

\begin{tabular}{c|c|c|c|c|c}
\hline Parameters & Moderators & QM & df & p-value & $\boldsymbol{I}^{2}$ accounted \\
\hline \multirow{5}{*}{ FC } & Study continent & 19.9 & 2 & $p<0.001$ & 25.61 \\
& Study country & 44.87 & 9 & $p<0.001$ & 41.20 \\
& Duration of supplementation & 15.5 & 5 & $p=0.0084$ & 16.42 \\
& Supplementation level & 23.8 & 2 & $p<0.001$ & 29.56 \\
& Broiler breed used & 7.04 & 7 & $p=0.425$ & 0.24 \\
\hline \multirow{5}{*}{ FCR } & Study continent & 7.80 & 2 & $p=0.0202$ & 12.63 \\
& Study country & 9.71 & 8 & $p=0.286$ & 4.24 \\
& Duration of supplementation & 2.41 & 4 & $p=0.66$ & 0.00 \\
& Supplementation level & 10.81 & 2 & $p=0.0045$ & 18.92 \\
& Broiler breed used & 10.8 & 6 & $p=0.094$ & 10.42 \\
\hline \multirow{5}{*}{ BWG } & Study continent & 7.76 & 2 & $p=0.021$ & 12.63 \\
& Study country & 9.71 & 8 & $p=0.286$ & 4.24 \\
& Duration of supplementation & 2.41 & 4 & $p=0.66$ & 0.00 \\
& Supplementation level & 10.8 & 2 & $p=0.0045$ & 18.92 \\
& Broiler breed used & 10.8 & 6 & $p=0.0944$ & 10.42 \\
\hline
\end{tabular}

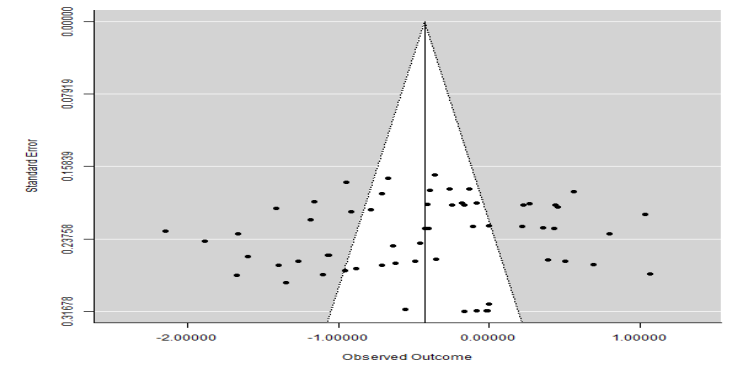

A

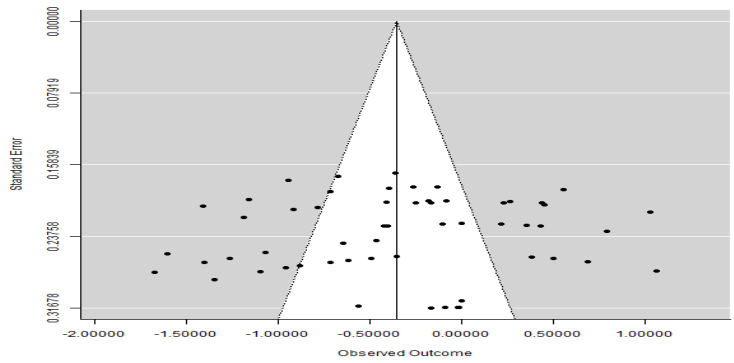

B

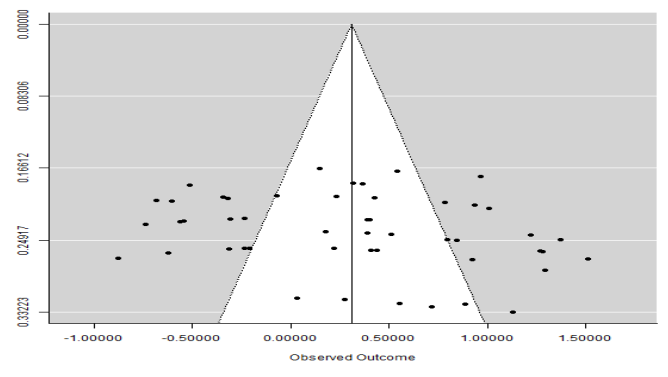

$\mathrm{C}$

Figure 8. Funnel plots of the effect of yeast on $F C(A), F C R(B)$ and $B W G(C)$ in broiler chickens

\section{Analysis of moderators}

The current meta-analysis disclosed an important association between yeast supplementation in broilers and some elements of our selected explanatory variables. This revealed that the moderators chosen were responsible for the inconsistency of results reported in broiler chickens fed probiotic yeast supplemented diets. There is 
significant relationship between probiotic (yeast) supplementation and FC, FCR and BWG in broiler chickens for studies performed in Asian and Europe. However, studies undertaken in Europe found a bigger relationship (FC, $d=0.993$; FCR, $d=0.993$; BWG, $d=0.838$ ) than those conducted in Asia. The effect of yeast on FC, FCR and BWG in broilers for studies conducted in Africa had no significant association. The observed disparity between the production indices of broiler chickens from studies undertaken in Africa and those performed in Europe and Asia can be partially attributed to differences in the environmental conditions of the three study continents. The environmental conditions hampering chicken performance and health include temperature, relative humidity, light and housing system (Elijah and Adedapo, 2006). Environmental temperatures have a negative impact on the survival and success of the broiler production. Broiler chickens are susceptible to environmental change because there is a narrow range of thermal conditions under which they can maintain a stable body temperature. However, no data was reported on the weather conditions of the study countries and continents as at the time the investigated was conducted. The failure of the authors of the study included in the meta-analysis to report the weather condition of the study region as at the time the study was carried out was the reason we could not identify the specific variables that might have been accountable for the differences in the productivity of broilers raised in Africa compared to those raised on the other two continents. The current meta-analysis also found that there was significant association effect of yeast on FC and FCR in broilers raised in Egypt, India, Pakistan, Iraq and turkey, whereas for BWG it was evident on studies undertaken in India, Iraq and Turkey. Yeast effect on FC and FCR was found in studies which lasted for 21, 35 and 42 days. However, there was no beneficial effect of yeast on studies that lasted 28 and 56 days. Enhancement in FC and FCR for studies that lasted for 21 days translates to an increase in body weight gain in broiler chickens. This indicate that study continent, study country, duration of supplementation are the limiting factors in several of the studies included in the meta-analysis. The level of yeast supplementation is a determinant in many studies and has led to differences in the outcomes reported by the various authors (Frizzo et al., 2011; Ezema and Ugwu, 2014). In this study, the beneficial activities of yeast on FC, FCR and BWG were shown in studies that fed diet supplemented with yeast at the rate of $<10 \mathrm{~g} / \mathrm{kg}$ feed. The Ross and Cobb broiler type had enhanced FCR and BWG with less feed intake, whereas Arbor acre had enhanced FCR, which did not translate to increased body weight gain in the current meta-analysis.

\section{Source of heterogeneity and publication bias}

This meta-analysis included research conducted in several parts of the world. In this context, the generalization and validity of the conclusions reached are strong. Potential biases, however, such as publication bias and heterogeneity were evident in the present meta-analysis and this was anticipated as most of the studies were undertaken in 10 study countries drawn from 3 continents. Substantial heterogeneity was recorded, sensitivity and stratified analysis fail to fix the issue. Results of meta-regression analysis showed that explanatory variables (study continent, study country, duration of yeast supplementation, yeast supplementation level and breed of broiler used) accounted for most of the variations among the studies included in the meta-analysis. For FC, FCR and BWG, the Rosenberg Nfs is 3138, 964 and 1913 respectively, which is 9, 4 and 6 times higher the threshold of $320(5 \times 62+10), 255(5 \times 49+10)$ and $305(5 \times 59+10)$ required to consider the mean effect size robust. Thus, publication bias was not an issue 
in the current meta-analysis since a relatively large number of unpublished studies would be required to alter significant impacts of yeast supplementation on broiler chicken productivity.

\section{Conclusion}

This meta-analysis provided baseline information on guidelines to standardize the experimental designs of future trials on the effect of probiotic-yeast supplementation on broiler chicken productivity. Results found that adding yeast to the broiler chicken diet at a level less than $10 \mathrm{~g} / \mathrm{kg}$ feed improved the productivity of broiler chickens. There was also a significant association effect between probiotic-yeast and explanatory variables. These results will encourage feed producers, poultry nutritionists, and farmers to make informed choices about the use of yeast in broiler chicken diets as an alternative feed additive instead of antibiotics. More research is, however, needed to ascertain the effect of yeast supplementation on quality characteristics of broiler chicken meat using meta-analytical approach.

\section{REFERENCES}

[1] Adene, D. F., Oguntade, A. E. (2006): Poultry Sector Country Review. - FAO Animal Production and Health Division, Emergency Centre for Transboundary Animal Diseases Socio Economics, Production and Biodiversity Unit, Rome.

[2] Ahmed, M. E., Abbas, T. E., Abdlhag, M. A., Mukhtar, D. E. (2015): Effect of dietary yeast supplementation on performance, carcass characteristics and some metabolic responses of broilers. - Animal and Veterinary Science 3(5-1): 5-10.

[3] Al-Mansour, S., Al-Khalf, A., Al-Homidan, F. M. M. (2011): Feed efficiency and blood hematology of broilers chicks given a diet supplemented with yeast culture. International Journal of Poultry Science 10(8): 603-607.

[4] Aluwong, T., Raji, M. A., Hassan, B. F., Kawu, M. U., Kobo, P. I., Ayo, J. O. (2012): Effect of different levels of supplemental yeast on performance indices and serum biochemistry of broiler chickens. - The Open Conference Proceeding Journal 3(Suppl 1M7): 41-45.

[5] Apata, D. F. (2008): Growth performance, nutrient digestibility and immune response of broiler chicks fed diets supplemented with a culture of Lactobacillus bulgaricus. Journal of Science Food and Agriculture 88: 1253-1258.

[6] Atul Shankar, K. P., Omprakash, A. V., Kirubakaran. J. J., Hudson, G. H. (2017): Effect of dietary yeast supplementation on the production performance of broilers. International Journal of Advanced Biological Research 7(2): 222-228.

[7] Awad, W. A., Bohm, J., Razzazi-Fazeli, E., Ghareeb, K., Zentek, J. (2006): Effect of addition of a probiotic microorganism to broiler diets contaminated with deoxynivalenol on performance and histological alterations of intestinal villi of broiler chickens. Poultry Science 85: 974-979.

[8] Borenstein, M., Hedges, L. V., Higgins, J. P. T., Rothstein, H. R. (2009): Introduction to Meta-analysis. - John-Wiley \& Sons Ltd., Chichester, pp.17-125.

[9] Bozkurt, M., Kucukyilmaz, K., Cath, A. U., Cinar, M. (2009): Effect of dietary mannan oligosaccharide with or without oregano essential oil and hop extract supplementation on the performance and slaughter characteristics of male broilers. - South African Journal of Animal Science 39: 223-232.

[10] Buba, W., Olugbemi, T. S., Omage, J. J., Duru, S., Iyiola-Tunji, A. O. (2016): Performance of broiler chickens fed varying levels of baker's yeast (Saccharomyces 
cerevisiae) during the hot season in the northern guinea savannah of Nigeria. - Journal of Animal Production Research 28(1): 215-226.

[11] Chand, N., Ihsanuddin, A., Khan, R. U. (2014): Replacement of soybean meal with yeast single cell protein in broiler ration: the effect on performance traits. - Pakistan Journal of Zoology 46(6): 1753-1758.

[12] Chen, C. Y., Chen, S. W., Wang, H. T. (2017): Effect of supplementation of yeast with bacteriocin and Lactobacillus culture on growth performance, caecal fermentation, microbiota composition, and blood characteristics in broiler chickens. - AsianAustralasian Journal of Animal Science 3: 211-220.

[13] Choudhari, A., Shinde, S., Ramteke, B. N. (2008): Prebiotics and probiotics as health promoter. - Veterinary World 1: 59-61.

[14] Costa, M. C., Bessegatto, J. A., Alfieri, A. A., Weese, J. S., Filho, J. A. B., Oba, A. (2017): Different antibiotic growth promoters induce specific changes in the cecal microbiota membership of broiler chicken. - PLoS ONE 12(2).

[15] DerSimonian, R., Laird, N. (1986): Meta-analysis in clinical trials. - Controlled Clinical Trials 7: 177-188.

[16] Dohoo, I., Martin, W., Stryhn, H. (2003): Veterinary Epidemiologic Research. - AVC Inc., Prince Edward Island, Canada.

[17] El Fatah, S. F. A. (2003): Effect of various yeast levels on broiler performance. - M.Sc. Thesis, University of Khartoum.

[18] Elijah, O. A., Adedapo, A. (2006): The effect of climate on poultry productivity in Ilorin Kwara State, Nigeria. - International Journal of Poultry Science 5(11): 1061-1068.

[19] Ezema, C. (2013): Probiotics in animal production: a review. - Journal of Veterinary Medicine and Animal Health 5(11): 308-316.

[20] Ezema, C., Ugwu, C. C. (2014): Probiotic effects of Saccharomyces cerevisiae on nutrient digestibility and $\mathrm{pH}$ of the gastrointestinal tract of broilers. - Proceedings of the International Conference on Beneficial Microbes ICOBM2014: Microbes for the Benefits of Mankind, May 27-29, Parkroyal Penang Resort, Penang, Malaysia, A-3, pp 10-13.

[21] Food and Agriculture Organization of the United Nations (FAO) (2016): The FAO Action Plan on Antimicrobial Resistance 2016-2020. - Food and Agriculture Organization of the United Nations, Rome.

[22] Frizzo, L. S., Zbrun, M. V., Soto, L. P., Signorini, M. L. (2011): Effects of probiotics on growth performance in young calves: a meta-analysis of randomized controlled trials. Animal Feed Science and Technology 169: 147-156.

[23] Gadde, U., Kim, W. H., Oh, S. T., Lillehoj, H. S. (2017): Alternatives to antibiotics for maximizing growth performance and feed efficiency in poultry: a review. - Animal Health Research Reviews 18(1): 26-45.

[24] Gao, P., Chen, M., Zheng, S., Wang, L., Huang, S., Xiaoquan, S., Xu, J., Zhang, H. (2017): Feed additive probiotics accelerate yet antibiotics delay intestinal microbiota maturation in broiler chicken. - Microbiome 5(91): 1-14.

[25] Gomes, L. C., Alcalde, C. R., Lima, L. R., Lima, L. S., Souza, R., Possamai, A. P. S. (2014): Nutritive value of diets containing inactive dry yeast for lactating Saanen goats. Revista Brasileira de Zootecnia 43(1): 36-43.

[26] Haghighi, H. R., Gong, J., Gyles, C. L., Hayes, M. A., Zhou, H., Sanei, B., Chambers, J. R., Sharif, S. (2006): Probiotics stimulate the production of natural antibodies in chickens. - Clinical Vaccine Immunology 13: 975-980.

[27] Higgins, J., Thompson, S. G., Deeks, J. J., Altman, D. G. (2003): Measuring inconsistency in meta-analyses. - British Medical Journal 327: 557-560.

[28] Higgins, J. P. T., Deeks, J. J. (2011): Chapter 7: Selecting Studies and Collecting Data. In: Higgins, J. P., Green, S. (eds.) Cochrane Handbook for Systematic Reviews of Interventions Version 5.1.0 (updated March 2011). The Cochrane Collaboration 2011. http://handbook.cochrane.org/ (accessed: $10^{\text {th }}$ September 2019). 
[29] Hooge, D. M. (2004): Meta-analysis of broiler chicken pen trials evaluating dietary mannan oligosaccharide, 1993-2003. - International Journal of Poultry Science 3: 163174.

[30] IntHout, J., Ioannidis, J. P., Borm, G. F. (2014): The Hartung-Knapp-Sidik-Jonkman method for random effects meta-analysis is straightforward and considerably outperforms the standard DerSimonian-Laird method. - BMC Medical Research Methodology 14: 25. doi: 10.1186/1471-2288-14-25.

[31] Jennions, M. D., Lortie, C. J., Rosenberg, M. S., Rothstein, H. R. (2013): Chapter 4: Publication and Related Bias. - In: Koricheva, J., Gurevitch, J., Mengersen, K. (eds.) Handbook of Meta-Analysis in Ecology and Evolution. Princeton University Press, Princeton, pp. 207-236.

[32] Kabir, J., Umoh, V. J., Audu-okoh, E., Umoh, J. U., Kwaga, J. K. P. (2004): Veterinary drug use in poultry farms and determination of antimicrobial drug residues in commercial eggs and slaughtered chicken in Kaduna State, Nigeria. - Food Control 15: 99-105.

[33] Koricheva, J., Gurevitch, J., Mengersen, K. (2013): Handbook of Meta-Analysis in Ecology and Evolution. - Princeton University Press, Princeton.

[34] Lean, I. J., Rabiee, A. R., Duffield, T. F., Dohoo, I. R. (2009): Invited review: use of meta-analysis in animal health and reproduction: methods and applications. - Journal of Dairy Science 92: 3545-3565.

[35] Manal, K. A. (2012): Effect of dietary yeast supplementation on broiler performance. Egyptian Poultry Science 32(I): 95-106.

[36] Mohamed, E. A., Talha, E. A., Mojahid, A. A., Dafaalla, E. M. (2015): Effect of dietary yeast (Saccharomyces cerevisiae) supplementation on performance, carcass characteristics and some metabolic responses of broilers. - Animal and Veterinary Science 3(5-1): 5-10.

[37] Mohamed, S., Abdalla, A., Mukhtar, A. M. (2016): Effect of commercial (Y-MOS) yeast on performance and carcass characteristics of broiler chicks. - World Journal Pharmacy and Pharmaceutical Science 5(6): 168-179.

[38] Musa, H. H., Wu, S. L., Zhu, C. H., Seri, H. I., Zhu, G. O. (2009): The potential benefits of probiotics in animal production and health. - Journal Animal and Veterinary Advance 8: 313-321.

[39] Njeru, H. K. (2013): Effects of enzyme complex (Allzyme SSF) and yeast metabolites (Diamond V XPC) on performance, immune responses, gastrointestinal morphology and intestinal microbiota in broiler chicken (Gallus domesticus). - MSc. Thesis, University of Nairobi.

[40] Ogbuewu, I. P., Okoro, V. M., Mbajiorgu, E. F., Mbajiorgu, C. A. (2019): Yeast (Saccharomyces cerevisiae) and its effect on production indices of livestock and poultry a review. - Comparative Clinical Pathology 51(2): 669-677.

[41] Osman, A. E. (2010): Effect of dietary supplementation of yeast (Saccharomyces cerevisiae) on performance and carcass characteristics of broiler chicks. - M.Sc. Thesis, University of Khartoum.

[42] Oyedeji, J. O., Ajayi, H. I., Egere, T. (2008): The effects of increasing levels of yeast culture (Levucel SB) in a high fibre diet on the performance and nutrient retention in broiler chicks. - Asian Journal Poultry Science 2(1): 53-57.

[43] Paryard, A., Mahmoudi, M. (2008): Effect of different levels of supplemental yeast (Saccharomyces cerevisiae) on performance, blood constituents and carcass characteristics of broiler chicks. - Journal of African Agricultural Research 3(12): 835842.

[44] Piątkowska, M., Jedziniak, P., Żmudzki, J. (2012): Residues of veterinary medicinal products and coccidiostats in eggs: causes, control and results of surveillance program in Poland. - Polish Journal of Veterinary Science 15(4): 803-812.

[45] Priya, B. S., Babu, S. S. (2013): Effect of different levels of supplemental probiotics (Saccharomyces cerevisiae) on performance, haematology, biochemistry, microbiology, 
histopathology, storage stability and carcass yield of broiler chicken. - International Journal of Pharmaceutical and Biological Archives 4(1): 201-207.

[46] Saulnier, D. M. (2007): Identification of prebiotic fructooligosaccharide metabolism in Lactobacillus plantarum WCFS1 through microarrays. - Applied and Environmental Microbiology 73: 1753-1765.

[47] Schneitz, C. (2005): Competitive exclusion in poultry - 30 years of research. - Food Control 16: 657-667.

[48] Shareef, A. M., Al-Dabbagh, A. S. A. (2009): Effect of probiotic (Saccharomyces cerevisiae) on performance of broiler chicks. - Iraqi Journal of Veterinary Science 23(1): 23-29.

[49] Spring, P., Wenk, C., Dawson, K. A., Newman, K. E. (2000): The effects of dietary mannanoligosaccharides on caecal parameters and the concentrations of enteric bacteria in the ceca of Salmonella-challenged broiler chicks. - Poultry Science 79: 205-211.

[50] USDA (2018): National Nutrient Database for Standard Reference. Full Report (All Nutrients) 18375, Leavening Agents, Yeast, Baker's, Active Dry. - USDA, Washington.

[51] Wallace, B. C., Lajeunesse, M. J., Dietz, G., Dahabreh, I. J., Trikalinos, T. A., Schmid, C. H., Gurevitch, J. (2016): OpenMEE: intuitive, open-source software for meta-analysis in ecology and evolutionary biology. - Methods Ecology and Evolution 8: 941-947.

[52] Yalcın, S., Eser, H., Yalcın, S., Cengiz, S., Eltan, O. (2013): Effects of dietary yeast autolysate (Saccharomyces cerevisiae) on performance, carcass and gut characteristics, blood profile, and antibody production to sheep red blood cells in broilers. - Journal of Applied Poultry Research 22: 55-61.

[53] Yoon, C., Na, C. S., Park, J. H., Han, S. K., Nam, Y. M., Kwon, J. T. (2004): Effect of feeding multiple probiotics on performance and fecal noxious gas emission in broiler chicks. - Korean Journal of Poultry Science 3: 229-235. 